Revista lus et Praxis, Año 20, № 2, 2014, pp. 71 - 108

ISSN 0717 - 2877

Universidad de Talca - Facultad de Ciencias Jurídicas y Sociales

"Sobre la estructura dogmática

de los delitos de falsedad en el proceso"

Javier Wilenmann von Bernath

Trabajo recibido el 27 de febrero y aprobado el 20 de mayo de 2014

\title{
Sobre la estructura dogmática de los delitos de falsedad en el proceso*
}

ON THE GENERAL STRUCTURE OF PERJURY AND OFFERING OF FALSE EVIDENCE

JaVier Wilenmann VON BeRnath**

Resumen

El presente artículo despliega una reconstrucción dogmática de los delitos de falsedad procesal. La reconstrucción dogmática es efectuada a partir de una comprensión estructural de las teorías de la declaración falsa: su objeto es definir los elementos de establecimiento de una relación comparativa cuya defraudación implica satisfacción del tipo objetivo del falso testimonio. Dicha tarea es efectuada por el artículo.

\section{AbSTRACT}

The present paper analyses perjury and other falsehood crimes against the administration of justice. The legal analysis puts forward a structural understanding of the theories of false declaration in German law: such theories define the elements of comparison whose lack of correspondence implies perjury. This reconstruction is undertaken in relationship to Chilean law.

Palabras Clave

Derecho penal, Delitos de falsedad, Falso testimonio, Falsificación de pruebas

KEYWORDS

Criminal law, Falsehood, Perjury

\footnotetext{
* Estoy en deuda ante todo con Fernando Atria por una conversación que tuve con él respecto a los criterios de reconocimiento penales y procesales del testimonio y que me ayudaron a formular de forma más clara mi argumento.

** Profesor de la Facultad de Derecho de la Universidad Adolfo Ibáñez (Santiago, Chile). Doctor (AlbertLudwigs-Universität-Freiburg [summa cum laudae], Alemania), LLM (Universität Regensburg, Alemania). Correo electrónico: javier.wilenmann@uai.cl.
} 


\section{Introducción}

El estudio dogmático del falso testimonio en Chile traiciona la historia de la institución. La larga historia moral y penal del falso testimonio y del perjurio no encuentra equivalencia en su en general escueto tratamiento doctrinal ${ }^{1}$. Por supuesto, un fenómeno de esta clase sería sólo culturalmente reprochable si el tipo en cuestión no tuviera relevancia práctica ni teórica. El falso testimonio, y en general los delitos de falsedad probatoria, son sin embargo el único medio directo de mantenimiento de fiabilidad de una estructura institucional frágil; la falta de protección de esa fragilidad frente a las mentiras forma parte del catálogo eterno de denuncias de problemas que podrían hacer inminente la destrucción de nuestras instituciones. Así, Konrad Hellwig podía quejarse en el año 1908 de que el peligro central para el sistema de justicia se habría encontrado constituido por "la visión extendida de que la mentira es un arma de combate permitida en el proceso civil" 2 . Que, en forma mucho más clara, el sistema se hace completamente inviable si se acepta la mentira por parte de testigos, es algo que apenas admite ser discutido. Por ello, si la falta de estudio es indicativa de la falta de consideración práctica, entonces la falta de equivalencia actual entre la relevancia histórica del falso testimonio y su estado dogmático podría ser además sintomática de un problema institucional general. Si bien es cierto que la posibilidad de encontrar sentencias relevantes sobre falso testimonio y presentación de pruebas falsas permite mitigar este juicio, su falta de tratamiento dogmático sigue siendo un déficit.

El déficit que aqueja al estudio del falso testimonio en Chile tiene, además, efectos trascendentes. No se trata sólo de que exista cierta falta de claridad en relación con cuestiones estructurales complejas del tipo de falso testimonio, sino que ella impide disminuir la mayor complejidad que tienen los delitos de falsedad en general como categoría. Es decir, la ausencia de claridad dogmática respecto al tipo más simple, el falso testimonio, es al menos indiciaria de los problemas de claridad que se presentan en la dogmática nacional de los delitos de falsedad y que permiten mantener el juicio de Binding sobre la dogmática penal de su época: el enorme interés científico y la unidad estructural de los delitos de falsedad no impiden que "su configuración legislativa muestre enor-

\footnotetext{
${ }^{1}$ El interés histórico del falso testimonio puede ser visto no sólo en el vínculo con estudios hebreos, bíblicos y con la larga historia de modificaciones fundamentales que ha sufrido desde el derecho romano. Algo dogmáticamente menos significativo, pero sumamente ilustrativo, es el hecho de que nadie menos que LiszT (1876) haya escrito su habilitación en lo relativo a la historia del tipo.
}

2 Citado por SChmidt (1909), p. 39. 
mes vacíos y problemas de comprensión y que tanto la ciencia como la praxis se enfrenten a ellos con una inseguridad chocante" ${ }^{3}{ }^{3}$

En un artículo publicado anteriormente, cuyo objeto era iniciar una serie de revisión de la dogmática de los delitos de falsedad, di cuenta en abstracto de la estructura de los delitos de falsedad y de la forma en que la dogmática debe tematizarlos para permitir su tratamiento ${ }^{4}$. En particular, dicho artículo pretendía disolver los problemas aparentes vinculados al concepto de falsedad en sí, y mostrar que los problemas dogmáticos centrales de esta categoría se vinculan antes con la determinación de los pares en relaciones de comparación cuya calificación de discordancia implica la realización de una falsedad. El presente artículo tiene por pretensión concretar esa tarea en relación con el tipo más simple de la categoría, el falso testimonio, y sus parientes.

Para ello, en primer lugar presentaré una descripción de los delitos procesales de falsedad en el derecho chileno (2). En una segunda parte, hablaré del contenido estructural del tipo objetivo en el falso testimonio, es decir, el significado de la expresión "faltar a la verdad" en una declaración por parte de un testigo, para luego extender esa estructura a los delitos de falso peritaje, falsa traducción y presentación de pruebas falsas. (3) En tercer lugar, daré cuenta de los problemas de imputación del falso testimonio.

\section{El sistema de delitos procesales de falsedad}

\subsection{Historia dogmática}

Pese a la relativa homogeneidad que puede apreciarse en el reconocimiento moderno del castigo a la emisión de declaraciones falsas en contextos procesales, las condiciones de castigo del falso testimonio han tendido a variar por mezclarse, ya desde el derecho hebreo, representaciones religiosas vinculadas a la idea de juramento, representaciones institucionales vinculadas a la necesidad de mantener contextos de relativa fiabilidad cognitiva y el aspecto puramente civil de la protección del patrimonio en contextos de interacción que requieren de fiabilidad.

Esta mezcla de concepciones en la reconstrucción jurídica del falso testimonio es en especial apreciable en el derecho romano y en la recepción del castigo del falso testimonio en el derecho medieval, canónico y común. En el caso del derecho romano, los supuestos punibles de emisión de declaraciones falsas se habrían encontrado vinculados ante todo a la protección civil del patrimonio. Así, el castigo mundano de la producción de declaraciones falsas en el derecho

${ }^{3}$ BINDING (1904), p. 108.

${ }^{4}$ Wilenmann (2014). 
romano debía tener lugar ante todo bajo los títulos seculares e individuales del falsum y del estelionato ${ }^{5}$. El castigo de la mera lesión del juramento era, en cambio, generalmente asumido como de competencia divina ${ }^{6}$. El derecho romano habría conocido de esta forma un predominio del falso testimonio sobre el perjurio, y la comprensión del primero habría estado generalmente vinculada a la producción de perjuicio individual a una víctima natural ${ }^{7}$. Esto es especialmente cierto en el caso del falso testimonio que produce la muerte de un inocente, castigada de acuerdo a la lex Cornelia de sicariis. La exigencia de vínculo con un resultado de muerte y la pena de muerte impuesta al propio testigo falso hacen razonable asumir una comprensión del delito como participación (o incluso pragmáticamente como autoría mediata, ya que no había responsabilidad del adjudicador) en homicidio ajeno. Ese falso testimonio sería, con ello, en realidad una forma de homicidio ${ }^{8}$. Es cierto que la punibilidad del falso testimonio y de la inducción al falso testimonio, como formas de falsum, construidas a partir de la lex Cornelia de falsi y de sus complementos pueden relativizar el juicio de protección puramente individual frente a declaraciones falsas en el derecho romano 9 . Esto no hace, sin embargo, más que confirmar la descripción general del tratamiento romano del falso testimonio: comprensión casi exclusivamente secular y, dentro de ésta, preponderancia de la comprensión individual (protección del patrimonio y otros bienes individuales) por sobre la comprensión institucional.

\footnotetext{
${ }^{5}$ También la ausencia de punición del perjurio en procesos civiles se dejaría explicar según LıszT (1876), pp. 12-15, en relación con esta comprensión civil de la punición de declaraciones falsas. A diferencia no sólo de la comprensión del juramento expresada en el tratamiento medieval del perjurio, sino también en la comprensión moderna vinculada a la administración de justicia, el juramento romano clásico habría tenido una función contractual en interacciones civiles (juramento de las partes en procesos civiles): el juramento habría jugado ante todo el rol de permitir el término de un conflicto jurídico por medio de un compromiso. Con ello, la falsedad del juramento no es que no necesitara de protección, sino que era simplemente imposible: un acuerdo no puede ser falso. Tampoco la decadencia del sistema procesal clásico romano y la instauración del juramento como forma de refuerzo de la veracidad del testimonio habría producido una ampliación del castigo del perjurio. Al respecto MülLER (2000), p. 10.

${ }^{6}$ En detalle LiszT (1876), pp. 3 y ss.; 11 y ss. y 18 y ss. Véase también BeRner (1866), p. 506, y Müller (2000), pp. 9-14. En cambio, en contextos en que declaraciones prestadas bajo juramento no hacían referencia a dioses, sino al Emperador -una costumbre que se habría iniciado con Augusto y posteriormente se habría consolidado bajo Tiberio-, la posibilidad de considerarlo una afrenta a la majestad de éste hizo que esa forma de perjurio fuera considerada punible. Así Liszt (1876), pp. 15 y ss.

${ }^{7}$ Véase Liszt (1876), pp. 25 y ss.

${ }^{8}$ Así Müller (2000), p. 11, con referencias ulteriores.

${ }^{9}$ Así ante todo Liszt (1876), p. 37, quien reconocía un principio de protección de algo así como la fe pública en el derecho romano vinculado a la lex Cornelia de falsi. Sobre la controversia relativa a la naturaleza del falso testimonio, véase también MülLER (2000), pp. 11-14.
} 
En el derecho medieval y en el derecho canónico, las relaciones entre la reconstrucción civil y religiosa del falso testimonio tomaron la forma inversa: los títulos de punición de declaraciones falsas eran generalmente dependientes de la afectación del nombre de Dios dada por la lesión del juramento ${ }^{10}$. El falso testimonio habría tomado así la forma del perjurio ${ }^{11}$, el que habría sido reconstruido como una clase de injuria a Dios y, por lo mismo, se habría tratado de un delito en potencia de mayor gravedad que el asesinato, "ya que el asesino sólo mata al cuerpo, mientras que quien comete perjurio destruye incluso a su propia alma"12. La naturaleza divina del delito no impedía, por cierto, que la comisión de perjurio implicara la aplicabilidad de penas corporales graves, en general relativas a la extirpación del miembro con el que se habría expresado el perjurio (esto es, en general la lengua, pero también manos y dedos) ${ }^{13}$. Esta preponderancia del castigo del perjurio se mantuvo en el derecho común. Así, el artículo 107 de la Carolina ${ }^{14}$, sistematizado entre los delitos contra Dios, establecía como castigo a la comisión de perjurio la extirpación de una mano o de un dedo (el dedo del juramento "Schwurfinger"). En cambio, el falso testimonio sólo era punible de por sí cuando diera lugar al castigo de inocentes (artículo 68). Lo anterior no quiere decir que fuera unánime la comprensión religiosa

\footnotetext{
10 Berner (1866), p. 506. y Müller (2000), pp. 14-15 (en el derecho germánico). Sobre el fundamento de punición del perjurio en el derecho canónico y común, véase pp. 16 y ss.

11 La primacía del perjurio por sobre el falso testimonio en el derecho común (y también, antes, en el derecho franco) se dejaría, por cierto, explicar por una sencilla razón práctica: la generalización de la obligación de jurar antes de prestar testimonio habría convertido a todo testimonio en declaración juramentada y, con ello, a todo falso testimonio en perjurio. Así Liszt (1876), pp. 81-82. Relativizando la ausencia de distinción, MülLeR (2000), pp. 20-21.

12 Citado por Liszt (1876), p. 10.

${ }^{13}$ En detalle Liszt (1876), pp. 64 y ss. De acuerdo al estudio de Liszt, el derecho alemán se habría encontrado ya en la Edad Media divido en el tipo de castigo aplicable al perjurio: mientras las ciudades sur-alemanas (desde Praga hasta Viena, pasando en particular por Baviera) habrían previsto castigos corporales particularmente fuertes para los casos de perjurio, las ciudades del norte de Alemania habrían previsto consecuencias civiles y penas auxiliares de incapacidad para ser testigo. Ello se debería, en todo caso, a diferencias en la distribución de competencia de tribunales eclesiásticos y laicos: en especie de delicta mixta, el perjurio habría implicado competencia de tribunales eclesiásticos y laicos. La ausencia de penas corporales laicas en el norte implicaría simplemente mayor reserva de competencia en el tratamiento del perjurio.

${ }^{14}$ La Constitutio Criminalis Carolina, promulgada por la Dieta Imperial (el Reichstag) en Ratisbona en 1532 en nombre del Emperador Carlos V (por ello "Carolina"), es la primera legislación penal común del Imperio y un texto central en el desarrollo del derecho penal común pre-reformado. Aunque la fragmentación política del Imperio y la presencia de una cláusula de aplicación subsidiaria hizo que no tuviera la influencia práctica directa que podría esperarse de una especie de codificación penal, sigue siendo una de las principales fuentes de estudio del derecho penal de inicios de la modernidad. Sobre la historia legislativa de la Carolina véase MAIHOLD (2006), pp. 76-78. Sobre su influencia véase MAIHOLD (2006), pp. 82 y ss.
} 
del castigo de la mentira. Es cierto que también en el derecho común puede apreciarse una comprensión patrimonial derivada de la doctrina del falsum ${ }^{15}$. Pese a ello, es incontrovertible la preponderancia de la comprensión religiosa del castigo de la mentira por sobre la comprensión patrimonial.

De acuerdo a la tesis de Liszt, el comportamiento inverso de la cultura jurídica medieval y moderna temprana en relación a la cultura jurídica romana -preponderancia del falso testimonio por sobre el perjurio en el primer caso, relación inversa en el segundo- sería una prueba crucial de la comprensión inversa que ambos tenían de sus representaciones de las relaciones entre Estado y religión: la sentencia de Tiberio, "que los dioses se preocupen ellos mismos de las injurias divinas", sería así representativa del vínculo instrumental establecido en particular durante el Imperio Romano entre Estado y religión, mientras que el derecho medieval, y ante todo aquí el derecho alemán medieval, habría entendido al revés al Estado como fuente de protección de la religión ${ }^{16}$.

Esta mezcla de fuentes y de concepciones relativas al fundamento del castigo del falso testimonio que puede apreciarse hasta el derecho común se mantuvo, aunque con variaciones considerables, en su recepción moderna en la codificación. Así lo demuestran, en primer lugar, las reglas relativas a la pena del falso testimonio: un buen número de codificaciones, incluida la codificación chilena, mantuvo la regla de determinación de la pena proveniente del derecho hebreo, bajo la cual el castigo por la comisión de falso testimonio era, en algunos supuestos, equivalente al mal que habría amenazado a la víctima del falso testimonio. Así lo hacía, por ejemplo, el artículo 361 del Código Penal francés de 1810, el artículo 192 del Código Penal para el Reino de Baviera de 1861 o los artículos 215 y 216 del Código Penal belga de 1867. Si, como hoy, el falso testimonio fuera simplemente expresivo de la protección de un objeto institucional -la administración de justicia-, entonces una regla de esta clase sería extraña: la graduación de la pena depende aquí por completo de bienes individuales amenazados. Por cierto, si el perjurio fuera una injuria divina, el castigo tampoco debiera ser dependiente de intereses ajenos amenazados, sino que sería siempre el mismo (y siempre el más grave posible tanto por consideraciones propiamente teológicas, como sobre todo por consideraciones casi instrumentales ligadas a la puesta en peligro de toda la comunidad al gatillar el riesgo de una venganza divina -una representación extendida hasta el siglo XVIII del fundamento del castigo de las injurias a Dios-). La famosa fórmula de Feuerbach -"Que Dios sea injuriado, es imposible; que éste pretenda vengarse de los hombres por las injurias de éstos, es impensable; que los hombres de-

15 Al respecto, MülLeR (2000), pp. 23 y ss.

16 LIsZT (1876), pp. 3-4. 
ban producir la expiación del injuriante mediante la imposición de penas, es necedad"17-, expresiva del espíritu de fines del siglo XVIII y principios del siglo XIX en la representación de las relaciones entre religión y Estado, se encuentra casi completamente confirmada en el tratamiento de la época del perjurio: no puede ser una verdadera injuria a Dios, pero ello no significa que no tenga relevancia ante todo patrimonial. La vuelta a la graduación hebrea de la pena no es, por ello, expresiva de un mantenimiento de la concepción religiosa medieval ${ }^{18}$, sino de la pugna entre una comprensión individual y supraindividual (institucional) del falso testimonio ahora al menos parcialmente secular. La disputa de la modernidad dejó de ser, de esta forma, una disputa entre concepciones seculares y religiosas, pasando a convertirse en una disputa entre comprensiones individuales y supraindividuales del falso testimonio ${ }^{19}$.

La reconstrucción anterior puede ser confirmada mirando la recepción legislativa de las distintas propuestas dogmáticas de reconstrucción sistemática del falso testimonio. La dogmática de fines del siglo XVIII y del siglo XIX mantuvo una disputa entre teorías que todavía reconocían el fundamento del castigo en razones de orden religioso ${ }^{20}$, teorías que asociaban el castigo a condiciones institucionales de funcionamiento del Estado y de sociedades modernas ${ }^{21}$ y teorías que mantenían el vínculo romano con la protección del patrimonio ${ }^{22}$, todo lo cual se vio reflejado en distintos cuerpos legislativos. En la recepción legislativa, esta pugna terminó siendo, en lo esencial, una disputa entre las dos comprensiones seculares. Así, mientras el Allgemeines Landrecht prusiano de 1794, la Josefina -el Código Penal austriaco de 1787-, el Código Penal francés de 1810 o el Código Penal bávaro de 1813 (el Ilamado Código Penal de Feuerbach) vinculaban al falso testimonio a una forma de delito de engaño ${ }^{23}$, otros códigos penales de codificaciones tempranas o intermedias lo sistematizaban entre delitos institucionales (por ejemplo, el Código Penal para el Reino de Sajonia de 1838 o el Código Penal belga de 1867). Sólo excepcionalmente se mantuvo su sistematización con delitos con contenido religioso (por ejemplo, el Código Penal para el Reino de Sajonia de 1855).

\footnotetext{
17 Feuerbach (1812), § 303, p. 262.

18 En opinión de LiszT (1876), p. 129, el falso testimonio habría ya en la época de la Josefina (1787) dejado de ser considerado generalmente un delito religioso.

19 Sobre la disputa en la modernidad temprana, en detalle LiszT (1876), pp. 130 y ss.

20 Al respecto, véase sólo Müller (2000), pp. 28-29; y MüLleR (2012), Vor §§ 153 ff. Nm. 3.

21 Al respecto, véase sólo MüLLER (2000), pp. 31-38.

22 Véase Müller (2000), pp. 30-31; Müller (2012) Vor §§ 153 ff. Nm. 4-6.

23 Véase Vormbaum (1987), pp. 14-21.
} 
Pese a la influencia que la disputa sobre el fundamento de punición del falso testimonio tuvo en la codificación temprana, el derecho continental tendió a homogeneizar su tratamiento como un delito contra un interés supraindividual. A la imposición de la comprensión secular le siguió, de esta forma, la imposición de la comprensión institucional del falso testimonio.

Esta imposición paulatina de una regulación legal y, correlativamente, de una comprensión dogmática de los delitos de falso testimonio como formas de protección de la administración de justicia no es, por cierto, simplemente el resultado de su corrección sustantiva o de su lógica superior. Antes, la confirmación del falso testimonio como delito contra la administración de justicia es demostrativa de la mayor relevancia adquirida por éste con la instauración de sistemas procesales acusatorios o inquisitorios reformados y con los cambios culturales de la modernidad. El fenómeno aquí es sencillo: la administración de justicia continental durante la modernidad temprana tenía una dependencia funcional con la tortura, de la misma forma en que la confianza general pre-moderna y en la modernidad temprana era asegurada por medio de asunciones religiosas generales vinculadas al juramento. La modernidad ilustrada hizo desaparecer ambas bases: en el caso de la tortura, la gran reforma política del siglo XVIII permitió su abolición; en el caso de la prestación de confianza a través de la religión, el paulatino desencantamiento en la comprensión del juramento dejó de hacerla fiable. Con ello, la administración de justicia pasó en los hechos a depender del castigo de la producción de falsedad en sus pro$\operatorname{cesos}^{24}$ : sus equivalentes funcionales habían desaparecido.

En el caso del derecho chileno, su codificación tuvo lugar durante el proceso de establecimiento del falso testimonio como delito de afectación del funcionamiento de instituciones, pese a que su denominación como "administración de justicia" se encontrara todavía ausente. Siguiendo al Código Penal belga de 1867, el Título IV del Libro Segundo fue denominado "De los crímenes y simples delitos contra la fe pública", pero, siguiendo en esto al Código Penal español de 1848, se introdujo además en el mismo la idea de falsificaciones y, como categoría especial, al falso testimonio y al perjurio. La falta de limpieza de esta forma de clasificación es ciertamente criticable, pero ella misma supone un compromiso con la comprensión institucional del falso testimonio que es completamente correcto.

El acierto de la codificación chilena, en el sentido de dar cuenta de una comprensión institucional de los delitos de falsedad en el proceso, no se extiende a la regulación histórica de la pena en el falso testimonio. En su origen, los artículos 206 a 210 CP graduaban la pena dependiendo de la clase de proceso de que

$24 \mathrm{Al}$ respecto Vormbaum (1987), pp. 83-91. 
se tratara y, en caso de ser penal, de la relación entre la declaración falsa y la posición del reo, estableciendo en su caso más grave, esto es, en caso de que la declaración falsa produjera la condena o agravación de la pena del imputado y que ésta fuera mayor que la pena normal del falso testimonio contra el reo, la antigua regla de imposición de la misma pena que a la víctima, proveniente del derecho hebreo. En esta forma de determinación de la pena gradual al perjuicio posible o real de la víctima individual del delito existe, por cierto, una continuación póstuma de la influencia de las concepciones romanas (civiles) y hebreas del falso testimonio. Es decir, el Código Penal manifestaba en su origen de forma interna el conflicto entre al menos dos formas de comprensión del falso testimonio: mientras su clasificación parecía dar cuenta de la aceptación de la comprensión que tendió a imponerse en el derecho continental en el siglo XIX, las reglas de determinación de la pena eran todavía vinculables con las dos formas alternativas de comprensión. Pese a que esta regla sobrevivió por más de 100 años y se mantuvo vigente incluso un tiempo después de implementada la reforma procesal penal, la supervivencia póstuma de las otras formas de tratamiento del falso testimonio desapareció definitivamente con la modificación del sistema de determinación de la pena mediante la Ley $N^{\circ} 20.074$ en el año 2005. Con ello, se consolidó su tratamiento como delito contra un presupuesto de funcionamiento institucional.

\subsection{Su agrupación como delitos contra la administración de justicia}

A la luz de la evolución de la regulación legal chilena, la tesis de que el falso testimonio es un delito institucional ya no puede ser conflictiva dogmáticamente. Eso no quiere decir, sin embargo, que la identificación precisa del presupuesto institucional protegido sea auto-evidente. La conclusión, generalmente compartida por la doctrina nacional, en relación a que el falso testimonio sería un delito contra la administración de justicia ${ }^{25}$, requiere de explicación en un doble sentido. Por una parte, la descripción del objeto como "administración de justicia" mantiene un nivel de abstracción que hace necesaria su explicitación ${ }^{26}$. Por otra parte, la producción inmediata del vínculo funcional-institucional de la categoría bajo el concepto de administración de justicia, sin problematizar

\footnotetext{
25 Así, por ejemplo, Etcheberry (1998), pp. 134-136 y 184 y ss.; Rodríguez y Ossandón (2008), pp. 237 y ss.; Politoff et al. (2005), pp. 535 y ss. Al menos en el nombre, en contra GarRIDO Montt (2000), pp. 9 y ss., quien intenta vincular el bien jurídico con el nombre del título IV y, con ello, trata al falso testimonio como delito contra la fe pública.

${ }^{26}$ Esto lo demuestra ante todo la reconstrucción del sentido del concepto de administración de justicia en formas que o bien no dicen mucho o bien no permiten vincular distintos tipos que quieren explicarse como parte de la categoría con el concepto que debiera permitir agruparlos. Al respecto, en detalle WiLenMann (2011), pp. 551 y ss.
} 
demasiado sus alternativas, pasa demasiado rápido las controversias de historia dogmática sobre la reconstrucción funcional de la categoría de delitos a la que pertenece el falso testimonio una vez asumido su carácter institucional. Esa controversia se deja describir contraponiendo un concepto de la clase del concepto de "fe pública", centrada en la forma de los objetos que se protegen y defendida en una de sus versiones más consistente por Binding, y un concepto de la clase del concepto de "administración de justicia", centrada en el funcionamiento de ciertas instituciones y defendida en su versión tal vez más influyente por Liszt. A la luz del derecho positivo, resolver la controversia adjudicándola inmediatamente al bando de Liszt invierte la carga de la argumentación, ya que los conceptos utilizados por el derecho positivo se encuentran comprometidos antes con la idea de fe pública. Así, el concepto de administración de justicia sólo puede ser encontrado en el Código Penal en la descripción de una forma menor de prevaricación en sus artículos 224 y 225 número 3. Su utilización como criterio de descripción general de una categoría funcional de delitos tampoco tiene lugar en la regulación positiva, a diferencia del concepto de fe pública, el que aparece explícitamente en el nombre del Título IV. La tesis de la reconstrucción del falso testimonio a la luz del concepto de administración de justicia requiere, por ello, evaluar sus méritos frente a un rival que superficialmente aparece favorecido por la regulación positiva.

La primera forma de reconstrucción supraindividual centra su peso en la demostración de la existencia de un vínculo entre la estructura típica de ciertos delitos y la protección de ciertas formas como explicación funcional de esa coincidencia de estructuras típicas. En la tesis de Binding, el falso testimonio y en particular el perjurio serían delitos estructuralmente asimilables a los delitos de falsedad documental y de falsificación de moneda, por lo que todos podrían ser agrupados como delitos contra la confiabilidad de medios probatorios $^{27}$. La tesis de Binding tiene de esta forma un contenido doble: contiene una aseveración relativa a la identidad (o similitud) estructural de los delitos de falsedad documental, falsificación y de los delitos de declaración falsa; y contiene una segunda aseveración funcional, en el sentido de considerar que el objeto protegido en todos los casos es el mismo: la fiabilidad de medios probatorios $^{28}$. Central en la realización del vínculo entre ambas ideas en Binding

\footnotetext{
27 Binding (1904), pp. 110 y ss.

${ }^{28}$ Esta aseveración implica además una tesis negativa sobre la relación entre falso testimonio y administración de justicia: "El perjurio y la vulneración de otras formas de aseguramiento surrogatorias del juramento no tienen por cien veces nada que ver con la administración de justicia. Se trata en cambio, de declaraciones con contenido falso en documentos auténticos cuando la declaración o el informe se contiene también por escrito; corto: ambos tipos son formas propias de falsedades y pertenecen por ello estrechamente a la misma categoría que los delitos de falsedad documental." [BINDING (1911), p. 9].
} 
es la representación de que en todos estos casos se protegen las formas que garantizan confiabilidad probatoria. Con ello, la protección frente a declaraciones procesales falsas necesitaría de una forma (equivalente a las formas que se encuentran en la moneda o en la idea de documento público), la que vendría dada en este caso por el juramento.

La segunda forma de reconstrucción de los delitos disuelve la unidad funcional entre los delitos con estructura de falsedad. Con ello, ciertos delitos de falsedad podrían integrar categorías disimiles. En el caso del falso testimonio, en tanto delito cometido inmediatamente al producir prueba, el vínculo natural aparecería con la administración de justicia. Con ello, según Liszt, la existencia de una formalización de la declaración bajo los requisitos del juramento sería superflua: si de lo que se trata es de la protección de formas de determinación de la verdad por organismos estatales, el juramento sólo podría ser conceptualizado como un equivalente a (o un complemento de) la pena, es decir, como algo cuyo objeto es aumentar la probabilidad de una declaración verdadera. En materia penal, su función sólo podría consistir en servir como calificante en caso de haber existido juramento. El objeto de protección sería en todo caso siempre el mismo: la administración de justicia.

En la disputa respecto al concepto de bien jurídico protegido por los delitos de falso testimonio, la posición de Liszt se impuso de forma categórica ${ }^{29}$. La dogmática del siglo XX ha adoptado así crecientemente, casi al punto de la unanimidad, el concepto de administración de justicia en la reconstrucción de la categoría. Esa imposición se deja explicar ante todo en los problemas que presenta la segunda parte de la tesis de Binding. La orientación a la protección en la confianza en ciertos medios con capacidad de rendimiento posterior en contextos judiciales es conflictiva, ante todo, en el caso de las falsedades documentales y de las falsificaciones. Que ellas tengan que tener potencialidad de incidencia en procesos probatorios posteriores es algo inverosímil en la consideración del disvalor de la falsedad en el tráfico cotidiano. Ello es todavía más claro en el caso de la falsificación de monedas. La tesis de Binding es, sin embargo, menos conflictiva en relación con el tratamiento que exige del falso testimonio. Si bien en la forma defendida por éste, la tesis hace diferencias en el tratamiento del perjurio frente al falso testimonio sin juramento $y$, al mismo tiempo, entre declaraciones producidas al menos también por escrito y declaraciones, por así decirlo, sin acta -diferencias que no sólo son incompatibles con el derecho chileno, sino que también en el derecho alemán dejaron de ser apreciables-, esas distinciones no son necesarias a la construcción de Binding ${ }^{30}$ :

${ }^{29}$ En detalle Müller (2000), pp. 38-40.

${ }^{30}$ Véase también Vormbaum (1987), pp. 145-146. 
si de lo que se trata es simplemente de la protección del valor probatorio de algo que debe ser fiable y cuya necesidad de fiabilidad se reconoce por alguna forma, la mera existencia de la posición formal del testigo es suficiente para necesitar protección. Pero su agrupación con los otros delitos de falsedad no puede, en cambio, tener lugar en un plano funcional. La tesis de Binding es a ese respecto efectivamente débil.

La disputa entre Liszt y Binding muestra que el concepto de administración de justicia tiene mayor rendimiento dogmático. Ese rendimiento se extiende, por una parte, a la ausencia de vínculos contra-intuitivos que generen problemas de reconstrucción dogmática. Por otra parte, el concepto de administración de justicia permite cumplir con la otra función que tiende a asignársele a la idea de bien jurídico en el estudio de la Parte Especial, a saber, permite entregar una explicación suficiente del fundamento del castigo de conductas que afectan condiciones de producción de la administración de justicia. Como la prestación entregada por la adjudicación puede ser reconstruida como parte esencial de un Estado moderno y, con ello, como condición necesaria de nuestra forma de relación libre, la cuestión de la legitimación de la protección penal de la administración de justicia no es de por sí problemática ${ }^{31}$. En esto, la doctrina nacional tiene razón al tratar al delito de falso testimonio como un delito contra la administración de justicia.

Ello no quiere decir, por cierto, que los delitos de particulares contra la administración de justicia se dejen legitimar de la misma forma que los delitos de funcionarios. Como la administración de justicia es una prestación estatal, la legitimación de obligaciones y sanciones de los funcionarios encargados de producirla requiere de muchas menos explicaciones que la legitimación de obligaciones y sanciones de particulares. El falso testimonio y la producción de pruebas falsas son, sin embargo, los paradigmas de delitos contra la administración de justicia que pueden ser producidos por particulares ${ }^{32}$. La eliminación de su tratamiento como delitos contra intereses individuales de un particular implica, además, que se trata de deberes positivos -es decir, no ligados a la obligación general de no dañar a otro- en relación con la producción de un bien institucional. Bajo el dogma de que sólo los deberes negativos se dejan justificar naturalmente en relación con los particulares, la imposición de un deber como el deber del testigo en relación a no declarar falsedades requiere de justificación.

\footnotetext{
${ }^{31}$ Al respecto, WiLENMANN (2011), pp. 556 y ss. Con numerosas referencias en relación a la incontrovertible legitimidad de la protección de la administración de justicia y, en particular, frente al falso testimonio, Vormbaum (1987), p. 97.

32 Esto es explícitamente asumido por parte de la doctrina nacional, que clasifica al falso testimonio como el primer caso de delito contra la administración de justicia cometido por particulares. Así Politoff et al. (2005), p. 535; y RodríGueZ y OSSANDÓN (2008), p. 237.
} 
Comprendido correctamente, ese era precisamente el punto del escepticismo no estructural de Binding en relación a la inclusión del falso testimonio entre los delitos contra la administración de justicia. Pero esa justificación puede ser buscada en la idea de proceso, algo en lo cual Binding y Liszt no tenían un desacuerdo real: la administración de justicia requiere no sólo imparcialidad y sujeción al derecho, sino también fiabilidad en la reconstrucción de hechos no perceptibles directamente.

La debilidad estructural de la administración de justicia moderna, en el sentido de que la corrección de sus decisiones depende de información cognitiva que los jueces no se encuentran en condiciones de percibir directamente, requiere de la imposición de obligaciones de colaboración y de sinceridad en todas aquellas actuaciones procesales que tienen entidad para producir efectos probatorios. Esto es: la forma de verificación cognitiva de hechos que se manifiesta en la argumentación jurídica y en el proceso es particularmente débil, por lo que requiere de estabilización normativa. Aún más: la asunción de que el proceso representa la forma más eficaz posible de reconstruir hechos pasados para la realización de un juicio es poco convincente. El proceso, y aquí sobre todo el proceso penal, tiene pretensiones de disciplina del Estado -y controvertidamente de privados- que limitan precisamente su eficacia. Con ello, sin la imposición de obligaciones de esta clase a privados, y sin que esa obligación se extienda a todos, la administración de justicia simplemente no podría funcionar.

La norma de comportamiento que tiene relevancia penal no es, sin embargo, la obligación completa impuesta por el sistema procesal al testigo en relación a declarar y no declarar falsedades, sino sólo la segunda (la obligación de sinceridad) $)^{33}$. La limitación de la obligación con refuerzo penal a la pura obligación de abstención puede explicarse, en parte, por referencia al opaco principio de protección subsidiaria de bienes jurídicos: ya que la obligación activa de declarar puede ser controlada procesalmente, la negativa a cumplir la obligación de declarar, en los casos en que la declaración es exigible, puede tener como consecuencia más benévola la pura coacción directa. Ese control procesal, sin embargo, sería sin dudas más eficiente si tuviera refuerzo penal. Antes, lo que se encuentra detrás de la distribución penal y procesal de funciones puede ser explicado históricamente: la disolución de la tortura tiene un vínculo directo con la ausencia de castigo por no prestación de colaboración con la administración de justicia.

El derecho penal, en los artículos 206 y siguientes CP, sólo castiga, por ello, el incumplimiento de la obligación de abstención en relación a produ-

${ }^{33}$ Véase Wilenmann (2011), pp. 569 y 570. 
cir falsedad. Y, precisamente por la necesidad de justificar la imposición de obligaciones institucionales a particulares, esa obligación sólo tiene entidad cuando se asume una posición formal en una situación formalizada, a saber, la posición de testigo en el contexto de un proceso ${ }^{34}$. Las distintas formas en que esta obligación general puede ser incumplida explican la sistematización interna del parágrafo 7 del Título IV.

La disputa entre Binding y Liszt y las razones de la imposición del último muestran, por otro lado, que el mayor rendimiento sistemático del concepto de administración de justicia en cuanto agrupación funcional no se extiende en nada a la consideración estructural de las categorías de delitos. El centro de la tesis de Binding, cuya influencia fue menor a la esperable tal vez precisamente por su insistencia inverosímil en la igualdad entre función (bien jurídico) y estructura (estructura de la falsedad), se mantiene en esto incólume. Parte de las pretensiones de este artículo, y de la serie de la que forma parte, es mostrar la capacidad de rendimiento dogmático que tiene esta tesis. Por ahora, ella puede ser demostrada a propósito de la discusión sobre los motivos de la sistematización del Código Penal chileno: si bien el "bien jurídico protegido" por el parágrafo 7 es irreductible a los parágrafos del Título IV, su agrupación se justifica estructuralmente. La clase de delitos del Título IV no es así funcional, sino estructural, y esa estructura es correctamente identificada por el derecho vigente.

\subsection{Estructuras generales de los delitos de falsedad procesal en el derecho chileno}

Desde su entrada en vigencia, el parágrafo 7 del Título IV ha organizado su estructura en relación a las condiciones específicas bajo las cuales la obligación de sinceridad se ve incumplida. En lo esencial, son dos los criterios de clasificación empleados por el Código Penal: la clase de proceso en el que tiene lugar la falsedad y la clase de actuación procesal en la que tiene lugar la producción de falsedad. En el primer caso, los criterios de clasificación son (i) proceso penal contra proceso civil contra procedimiento no contencioso; (ii) cuantía y, en el caso del proceso penal, (iii) relación de la actuación en cuestión con la posición del imputado. En el segundo caso, los criterios son testimonio (y desde la reforma de 2005, peritaje o traducción) contra prueba documental.

Aunque las dos formas de clasificación son relevantes para la determinación de las condiciones de procedencia de la punición, la clasificación por clase de actuación procesal (testimonio contra otras pruebas) no tiene ninguna relevancia para la graduación de la pena en procesos contenciosos, la que es casi completamente mimética en ambas hipótesis. Con ello, en la determinación de

${ }^{34}$ En el fondo similar RodríGuez y Ossandón (2008), pp. 238-239. 
la pena el único criterio relevante es la clase de proceso en la que se produjo la actuación falsa. Así, en el texto original del Código Penal, el falso testimonio en materia penal, y correlativamente la presentación de pruebas falsas (artículo 212), tenía como hipótesis básica el último supuesto del artículo 206, a saber, el falso testimonio a favor del reo en proceso por falta. A partir de este supuesto, los artículos 206 y 207 CP aumentaban en un grado la pena por cada circunstancia de calificación: un grado más por tratarse de simple delito, un grado ulterior por tratarse de crimen y un grado más de forma independiente en caso de ser declaración contra el reo. Además, el artículo 208 CP contenía una regla de graduación distinta en caso que la declaración contra el reo terminara con la imposición de una pena más grave: esa misma pena debía imponerse al testigo falso o a quien presentara pruebas falsas. En el caso del falso testimonio en materia civil, la pena dependía de la cuantía, mientras que la pena en caso de perjurio en actuaciones no contenciosas era uniforme.

Aunque la reforma del 2005 cambió completamente la forma de expresión de este sistema, su organización sigue siendo equivalente. Los artículos 206 y 207 CP establecen en lo esencial tres hipótesis: falso testimonio (o peritaje/ traducción) en materia civil o penal por falta (hipótesis básica presidio menor en su grado mínimo a medio y multa, más penas auxiliares para ciertos sujetos), una calificación por tratarse de proceso penal por simple delito o crimen y una regla de exasperación en caso de tratarse de declaración contra el imputado.

Este sistema se ve ligeramente modificado por las reglas del artículo 209 $\mathrm{CP}$ relativas a la graduación de la pena del falso testimonio en materia civil. El artículo contiene una hipótesis básica en caso de tener el juicio una cuantía menor a 4 UTM (presidio menor en su grado mínimo y multa) y una hipótesis calificada en caso de tener cuantía superior a esto (presidio menor en su grado medio y multa). Ello parece ser contradictorio con el artículo $206 \mathrm{CP}$, el que establece una pena única de presidio menor en su grado mínimo a medio y multa para el falso testimonio en materia civil. La única forma de interpretar ambas reglas de forma sistemáticamente consistente es considerar que se trata de una especificación de la regla más indeterminada (presidio menor en su grado mínimo a medio, sin distinción por cuantía) contenida en los artículos 206 y $207 \mathrm{CP}$ respecto al falso testimonio en materia civil ${ }^{35}$. Esto es, sin embargo, problemático en los casos de presentación de pruebas falsas, ya que el artículo 209 CP no tiene referencias a esta hipótesis típica. Si bien la relevancia de esta omisión es menor, ya que en cualquier caso se encuentra incluida en el artículo 207 CP, la asimetría en el tratamiento es difícilmente comprensible como otra cosa que un error legislativo. Algo similar sucede respecto a las hipótesis de

35 Así también Garrido Montt (2008), p. 118. 
declaraciones falsas en contextos no contenciosos. Los artículos 210 y 212 CP sólo incluyen hipótesis de falsedad en declaraciones (en materia no contenciosa en el artículo 210 y en todo otro caso de producción de declaración bajo juramento o promesa en el artículo 212), con lo que la presentación de pruebas documentales falsas en esos contextos no es punible.

Este sistema de reglas, que en apariencia es complejo, sólo produce variaciones relevantes en relación con la pena. En la determinación del contenido del tipo, el sistema tiene en realidad sólo dos hipótesis: "faltar a la verdad" 36 , descripción que el Código Penal aplica a los supuestos de declaraciones falsas, y "presentar pruebas falsas o adulteradas", aplicable a los demás supuestos. Los dos supuestos son, además, parcialmente equivalentes: una prueba que es falsa falta a la verdad, de la misma forma que un testigo que falta a la verdad es un testigo falso, como lo reconocía el antiguo artículo $208 \mathrm{CP}$ y el propio artículo 207 CP en su redacción actual. Todos los tipos centrales del parágrafo manifiestan, de esta forma, una dependencia con el núcleo de injusto "faltar a la verdad" o "producir falsedad", propio de los delitos de falsedad proposicional ${ }^{37}$.

No sucede exactamente lo mismo con algunas variaciones auxiliares que tuvieron lugar con la reforma. En particular, la unificación de la descripción de la acción típica del testigo, perito e intérprete hace que el concepto de "faltar a la verdad" del artículo 206 CP no sea completamente unívoco. Esto es evidente en el caso del intérprete: el intérprete sólo tiene una función procesal en la traducción, por lo que la norma de comportamiento no puede sino referirse a esa específica función y no, en cambio, a un concepto directo de falsedad. Por ello, los casos de falso peritaje y falsa traducción, junto con la presentación de pruebas no testimoniales falsas, serán tratados como casos especiales. La determinación del contenido del concepto de faltar a la verdad en el caso de la declaración es primaria en el análisis de los delitos de falsedad en el proceso.

\section{El contenido de injusto del falso testimonio y de los tipos emparentados}

\section{1. "Faltar a la verdad"}

El núcleo de injusto de los delitos de falsedad en el proceso es dependiente del concepto de verdad. La realización del tipo supone siempre la calificación

\footnotetext{
${ }^{36}$ Antes de la reforma del año 2005, el contenido del tipo era descrito con la fórmula "dar falso testimonio", la que hoy, tal vez por descuido, sólo se mantiene en el artículo $210 \mathrm{CP}$. La diferencia entre ambas fórmulas es irrelevante. De hecho, ya antes de la reforma la doctrina hacía constantemente referencia a la idea de verdad para definir el "dar falso testimonio". Por ejemplo así EtCheBerRy (1998), p. 190; GarRido MONTt (2000), p. 111 ("faltando a la verdad objetiva); y RodríGuez Y OSSANdón (2005), p. 247 ("faltando a la verdad").

37 Infra.
} 
de un acto determinado como alguna forma de "faltar a la verdad". Por supuesto, ese faltar a la verdad puede ser cometido de distintas formas: declarando, en el caso del falso testimonio, presentando documentos de contenido falso, en el caso de la presentación de pruebas documentales falsas, traduciendo mal, en el caso de la falsa traducción, etc. La estructura de determinación de la falsedad del objeto de la actuación varía. La dogmática particular de los delitos de falsedad en el proceso tiene por objeto el análisis de esas variaciones respecto del tipo respectivo. Pero en todos estos casos existe una estructura relacional dada por el concepto de faltar a la verdad: faltar a la verdad puede ser siempre reconstruido como la producción de correspondencia inexistente. La dogmática general de los delitos de falsedad tiene por objeto el análisis de esa estructura.

Cómo puede ser descrita la estructura de la falsedad, es algo que ya he expuesto con detalle en otro contexto ${ }^{38}$. Ella se deja resumir de la siguiente forma: falsedad en sentido estricto es la producción de enunciados institucionalmente relevantes que defrauden de forma imputable su propia pretensión ilocucionaria. La determinación de esa defraudación depende, por ello, de la identificación de la existencia de un enunciado relevante, de la identificación de una determinada pretensión de esa clase de enunciados, de la determinación de las condiciones de realización de esa pretensión en el enunciado particular y, finalmente, de la verificación de la defraudación particular. Si, existiendo un acto comunicacional relevante, las condiciones de realización no se cumplen, entonces el enunciado es falso de forma relevante. Ejemplo: una afirmación de hecho defrauda una pretensión ilocucionaria si lo afirmado, el estado de cosas descrito, no corresponde a una descripción correcta de ese mismo estado de cosas (o, de forma menos precisa, si lo descrito no tuvo lugar en la realidad).

La estructura supone, por lo mismo, siempre una comparación. Buena parte de la dogmática de los delitos de falsedad se reduce a la identificación de la estructura de esa comparación en los tipos respectivos. En general, es decir en relación a la estructura compartida por los tipos de la categoría, la estructura puede describirse por referencia a la comparación que se produce entre el sentido del acto en cuestión -qué es lo que afirmó, en el caso de una declaración-y un objeto de comparación asumido como correcto, en el sentido de que la no correspondencia entra ambos implica falsedad del acto -la descripción correcta, justificada, del mismo estado de cosas-. Los delitos de falsedad en sentido estricto (o falsedad proposicional), categoría de la que forman parte los delitos de falsedad en el proceso, suponen siempre la determinación de todos los elementos de esa comparación: condiciones bajo las cuales una actuación con contenido comunicativo es relevante desde el punto de vista de un tipo

${ }^{38}$ Wilenmann (2014), en lugares diversos. 
penal determinado -este es el rol que cumple la delimitación dogmática del concepto de "declaración"-; determinación del contenido de ese acto; y determinación del objeto de comparación de ese acto para determinar su falsedad. La especificación de esa estructura relacional, propia de todos los delitos de falsedad en su dogmática particular, puede ser explicada en su forma más sencilla en el falso testimonio ${ }^{39}$. Eso es lo que hacen las Ilamadas teorías de la declaración falsa, las que dan cuenta por ello de buena parte de la dogmática del falso testimonio.

\subsection{El concepto de declaración como centro del contenido de injusto del falso testimonio: las Ilamadas teorías de la declaración falsa}

Las teorías de la declaración falsa, el centro de la dogmática de los delitos de falso testimonio en la dogmática penal alemana, no son aplicaciones de disputas filosóficas sobre el concepto de verdad ${ }^{40}$. Al contrario, las disputas filosóficas sobre el concepto de verdad casi no tienen rendimiento dogmático ${ }^{41}$ : el derecho tiene que asumir, ya por su estructura institucional ${ }^{42}$, un concepto de verdad relacional por medio de la comparación entre enunciados cuya justificación está en disputa (el enunciado del testigo) y enunciados justificados (la reconstrucción coincidente o alternativa del juez en el proceso sobre falso testimonio), todos los cuales tienen el mismo objeto de referencia.

Las teorías de la declaración falsa son, en cambio, teorías relativas al objeto de referencia de esos enunciados, es decir, tienen por objeto especificar la composición analítica de los objetos que deben compararse para determinar la existencia de falsedad en declaraciones de testigos ${ }^{43}$. Es decir, se trata de la determinación de si la declaración (el portador de verdad o falsedad en este sentido, cuyas condiciones de identificación serán vistas en el próximo apartado) debe ser discordante con lo subjetivo del testigo (percepción original y recuerdo actual son los grandes candidatos de las Ilamadas teorías subjetivas, pero ambos pueden ser agrupados bajo el concepto impreciso de conocimien-

\footnotetext{
39 Así también Hilgendorf (1993), p. 547.

${ }^{40}$ Para una exposición más detallada, en español puede revisarse la traducción de STEIN (2008), en lugares diversos. Sobre las distintas posturas, véase sólo Paulus (1987), pp. 437 y ss., con innumerables referencias ulteriores; Müller (2012), § 153 Nm. 41 y ss.; y Vormbaum (2013), § 153 Nm. 60 y ss.

${ }^{41}$ Hilgendorf (1993), p. 558. Así también Müller (2000), p. 85. En contra Kaufmann (1992), pp. 127 y ss.

42 Al respecto, Wilenmann (2014).

43 Similar en la descripción del contenido de la disputa KüPER (2005), p. 31; MülleR (2000), pp. 82 y ss.; Vormbaum (1987), pp. 253 y ss.; Vormbaum (2013), § 153 Nm. 57 y ss.; Hilgendorf (1993), pp. 558-559; HRUSCHKA-KäsSer (1972), p. 710; PAulus (1987), p. 436-437; LeNCKNeR y BOSCH (2010), Vorbem. §§ 153 ff. Nm. 4; WOLF (1991), p. 177-178.
} 
to), y por lo mismo el enunciado de comparación del juez tiene por objeto una reconstrucción plausible de ese recuerdo o esa percepción atribuible, o con la "realidad" de los hechos respecto a los cuales éste declara ${ }^{44}$. Especificado, la comparación que da cuenta del contenido del falso testimonio tiene tres posibles objetos de referencia bajo dos modalidades a su disposición: el objeto de comparación es la realidad de los hechos sobre los que se declara (teorías objetivas), el recuerdo actual de los hechos (teorías subjetivas, cuya especificación puede ser designada como "subjetivas de fijación presente"45), la percepción original de los hechos (teorías subjetivas de fijación pasada), siendo el objeto respectivo invariablemente el mismo (teorías estrictas) o dependiendo del rol procesal (teorías de la obligación y otras teorías modificadas) o de la forma de la declaración (teorías contextuales) ${ }^{46}$.

Aunque semánticamente las teorías de la declaración falsa se presentan dependientes de tres variables que funcionan en un mismo nivel, se trata en realidad de una combinatoria de tres elementos con dos permutas: los tres objetos de comparación respectivos se ven especificados bajo las variables estricta/modificada y contextual/no contextual. Por ello, es posible sostener con sentido una teoría objetiva estricta contextual (por defecto, la declaración se compara con la realidad, a menos que el testigo declare estar dando cuenta sólo de su recuerdo o de su percepción) o una teoría subjetiva de fijación presente, modificada y contextual (aquello que se compara depende del rol procesal y de la forma de la declaración; en caso que la declaración sea derechamente afirmativa, el objeto de comparación es el recuerdo). Así, el número de teorías de la declaración falsa que pueden, en principio, ser sostenidas con sentido es 12 .

\footnotetext{
${ }^{44}$ Esta es la reducción conceptual tradicional para contraponer las teorías subjetivas a las teorías objetivas (reducidas a partir del concepto de realidad). Así, por ejemplo, Gallas (1957), p. 315; KaUfMANN (1992), pp. 119-120; KARGL (2003), p. 794; KINDHäUSER (2012), § 46 Nm. 14 y 17; KüPER (2005), pp. 31-32; Paulus (1987), p. 438; Otto (1984), p. 163; LenCKNer y Bosch (2010), Vorbem. §§ 153 ff. Nm. 4; Müller (2012), § 153 Nm. 42 y 47; crítico Vormbaum (2013), § 153 Nm. 60.; Wolf (1991), p. 178.

45 Paulus (1987), p. 438 las denomina teorías subjetivas estrictas. Esa nomenclatura induce, sin embargo, a confusiones, ya que la calificación estricta/modificada tiende a ser utilizada, a su vez, para determinar la variabilidad del objeto dependiendo del sujeto de la declaración. Aunque por cierto la variabilidad del objeto por referencia a expectativas subjetivas dadas por la posición del declarante tiene un común denominador evidente con la variabilidad dada por las expectativas dadas por la forma de la declaración, es más preciso distinguir ambos tipos de variantes.

${ }^{46}$ Con mayor detalle véase Kargl (2003), pp. 796 y ss.; Müller (2000), pp. 54 y ss.; Vormbaum (1987), pp. 253 y ss.; Paulus (1987), pp. 437 ss.; Отто (1984), pp. 161-162. La nomenclatura sólo es coincidente en contraponer objetivo a subjetivo. El etiquetamiento posterior de las teorías -en particular, de la teoría de la obligación y en general de toda modificación de las posturas iniciales- es extremadamente plurívoco y, en muchos casos, confuso. Por eso, he preferido reconstruirlo antes como combinación analítica que, suele ser el caso, como presentación semántica directa.
} 
En otro contexto ya di cuenta de las razones por las cuales en la determinación de los objetos de referencia mismos las teorías subjetivas son poco atractivas $^{47}$. Ello se deja resumir dando cuenta del carácter innecesariamente reactivo de las teorías subjetivas. El punto central de las teorías subjetivas es impedir la crítica al castigo por falso testimonio, en el sentido de que exigiría algo que no es exigible, a saber, que el testigo declare sobre la verdad tal como es. Aunque el argumento puede presentarse con sustento epistemológico -todo conocimiento es necesariamente representación, no realidad ${ }^{48}-$ y con sustento histórico en la fijación en elementos subjetivos del derecho canónico dado por el vínculo entre falsedad y el pecado de la mentira ${ }^{49}$, su problema crucial es de legitimación: parece inmediatamente injusto tratar como incorrecta la conducta del testigo que declara exactamente lo que percibió o recuerda, pese a que ello sea falso. Es decir, las teorías subjetivas pueden ser vistas como exigencias de incorporación de eventuales problemas de rendimiento de la memoria o de la percepción que pueden darse en un testigo en el tipo objetivo del falso testimonio ${ }^{50}$.

Si bien la exigencia de concesión de relevancia a los problemas de rendimiento es correcta, ella tiene lugar en cualquier caso de forma prácticamente necesaria en la imputación de falsedad al testigo: no hay dolo si el testigo percibió/ recuerda otra cosa o puede atribuírsele otra percepción/recuerdo. Quien sostiene una teoría subjetiva de la declaración cree que esto es muy poco: cuando hay problemas de rendimiento no habría ninguna infracción de obligación, por lo que la conducta no sería ni siquiera objetivamente típica ${ }^{51}$. Esa fijación inicial es correcta: el castigo por decir algo falso sin saber que es falso parece difícilmente justificable. Pero las teorías subjetivas parten de la base que la realización del tipo objetivo no imputable implica algún grado de reproche y/o la imputación de la infracción de una obligación. El problema de la crítica no se encuentra, por ello, sólo en su tratamiento del problema de Parte Especial correspondiente, sino en una asunción incorrecta de Parte General, a saber, que aquello que no resulta imputable es necesariamente expresivo de un reproche mínimo o, al menos, de relevancia normativa como infracción de alguna obligación. El falso testimonio demuestra precisamente que esa asunción es errada ${ }^{52}$. El objeto del dolo es justamente dar cuenta del cumplimiento de las condiciones situativas bajo las cuales la conducta objetivamente antinormativa se deja reconstruir como

\footnotetext{
${ }^{47}$ Lo que sigue puede encontrarse con mayor detalle en WiLENMANN (2014).

48 Locus classicus es BINDing (1904), p. 134.

49 Así Liszt (1876), p. 89. Véase también Binding (1904), p. 134.

${ }^{50}$ Con mayor detalle, Müller (2000), pp. 83-85.

51 Así Gallas (1957), pp. 317-319

52 Así también HruschKa y Kässer (1972), p. 710.
} 
verdadera infracción de la norma de comportamiento ${ }^{53}$; sin dolo (o, en caso de ser aplicable, imprudencia), no sólo no hay reproche alguno posible, sino que ni siquiera puede afirmarse la existencia de un injusto objetivo que dé lugar, por ejemplo, a reacciones no dependientes de la infracción de una obligación.

Lo anterior quiere decir: en la determinación del objeto de referencia al interior del concepto de falsedad en el falso testimonio, los problemas que deja la teoría objetiva son, en general, tematizados y resueltos por una comprensión correcta del dolo. La reacción en el tipo objetivo mismo, dada por la aceptación de una teoría subjetiva, es innecesaria y contraproducente. Esto deja, por cierto, todavía abierto el viejo problema denunciado por Binding, en relación a que el testigo que declara algo que cree falso, pero que resulta verdadero, no podría ser castigado sino por tentativa. La concesión de tanta relevancia a ese problema muestra, sin embargo, que las teorías subjetivas mantienen la fijación canónica en el castigo de la mentira. La referencia de Binding a lo "sorprendente" que resultaría ser este error de las teorías objetivas, ya que ya en el derecho canónico se llegaba a la supuesta solución correcta, confirma el punto ${ }^{54}$. En lo demás, en el problema central del reconocimiento de los problemas de percepción o recuerdo, un manejo adecuado del dolo permite solucionarlos. Precisamente por ello es que es necesario distinguir los problemas de imputación en el falso testimonio, tratados en la sección siguiente, de los problemas de tipo objetivo en sentido estricto. En la determinación del tipo objetivo, en cambio, la cuestión es mucho más sencilla de lo que aparece por la complejidad de la discusión: falsedad en el falso testimonio es simplemente no correspondencia entre declaración y realidad, la que se ve fijada por el enunciado justificado (por prueba) del juez en el proceso por falso testimonio ${ }^{55}$.

Más compleja es la discusión propia de la dogmática del falso testimonio -es decir, no extrapolable a otros delitos de falsedad proposicional-sobre las modificaciones que puede sufrir el objeto de referencia por consideraciones procesales. Aquí se trata de la revisión de la capacidad de producir variaciones

\footnotetext{
53 Al respecto, WilenMAnN (2013), sección 4. En lo referente al falso testimonio, precisamente por ello HRUSCHKA Y KäsSER (1972), p. 710; y LeNCKNER y BOSCH (2010), Vorbem. §§ 153 ff. Nm. 6; critican la confusión de los conceptos de "falsedad" -componente del tipo objetivo- e infracción de deber que subyace a toda teoría subjetiva. Similar KINDHÄUSER (2012), §46 Nm. 20.

54 BINDING (1904), p. 134 con nota 3.

${ }^{55}$ En Alemania, tanto la opinión dogmática dominante como la jurisprudencia sostienen una teoría de esta clase. Véase sólo KARGL (2003), p. 792, con referencias ulteriores. Entre nosotros, en el fondo similar GaRRIDO MONTt (2000), p. 113. En esto es poco precisa la descripción del tipo objetivo del falso testimonio que puede encontrarse en la jurisprudencia: "discrepancia entre los dichos del declarante y el conocimiento que éste tenga en cuanto a los mismos" (Corte de Apelaciones de San Miguel, Rol 1284-2008, 13 de octubre de 2008, p. 2). Esa definición recoge correctamente su estructura relacional pero, al igual que las teorías subjetivas, incorpora el tipo subjetivo al tipo objetivo de forma incorrecta.
} 
en el objeto de referencia por la forma de la declaración (teorías contextuales/ no contextuales) o por la expectativa existente respecto al declarante (estrictas/ modificadas). Una teoría objetiva estricta y no contextual sostiene que el objeto de comparación es siempre la realidad. Una teoría objetiva estricta pero contextual sostiene, en cambio, que la cuestión depende del contenido de la declaración: por defecto, el objeto de comparación es la realidad, ya que el contenido normal de una declaración se refiere a ello, a menos que el testigo declare que el objeto de su declaración es su recuerdo (borroso) o la percepción original (poco fiable). Una teoría modificada sostiene, a su vez, que el objeto de comparación depende de la expectativa procesal existente respecto al agente. Que las condiciones de verificación de la realización del tipo cambian en caso de peritos e intérpretes, por ejemplo, es claro a la luz de la regulación chilena, por lo que la aceptación de esas modificaciones no es conflictiva. Una teoría modificada puede sostener, más allá de esto, que la expectativa procesal cambia también, por ejemplo, en caso de testigos expertos.

Los conceptos auxiliares "contextual/no contextual" y "estricta/modificada" cumplen así la función dogmática de especificar el contenido de la teoría general (objetiva o subjetiva) respecto de la clase de situaciones que ellas mismas fijan, a saber, respecto de la propia contextualización que los testigos tienden a hacer de sus declaraciones, y respecto de sujetos cuyo rol procesal trasciende la mera declaración en sentido estricto del testigo normal. Ambas cuestiones merecen ser consideradas, por ello, por separado. Como la aceptación de cambio del objeto de referencia por contextualización incide sólo en ello, tematizaré a continuación esta cuestión. El problema de la aceptación de cambio de las condiciones de realización del tipo en relación con la posición del sujeto activo será analizado, en cambio, a propósito del falso peritaje y la falsa traducción, ya que se trata precisamente de ver hasta dónde se extiende la variabilidad del objeto de referencia en la determinación de falsedad a partir del cambio de expectativas procesales.

El argumento para sostener una teoría contextual es equivalente al argumento reactivo de las teorías subjetivas, pero en una versión que parece tener mayor apoyo positivo: si un testigo reduce la extensión de su declaración a su recuerdo ("recuerdo que ese día...", "creo recordar que ..."), entonces la falta de correspondencia con la realidad por problemas de rendimiento de la memoria (o de la percepción, en caso que la limitación sea esa) implica ausencia de falsedad: el testigo efectivamente recordaba eso y sólo afirmó que recordaba eso. El argumento es, por ello, formalmente correcto. Pero su relevancia es, por lo mismo, limitada: el paso del tipo subjetivo, cuando la declaración no la contextualiza el testigo, al tipo objetivo, cuando la declaración sí es contextualizada, tiene incidencias didácticas en la distinción entre verificación de cumplimiento de un tipo e imputación. En ambos casos, sin embargo, un problema de rendi- 
miento al que se le presta reconocimiento implica irrelevancia de la infracción (o aparente infracción) del testigo.

Lo anterior puede ser explicado de forma más precisa. Al igual que en la imputación de la declaración falsa como declaración dolosa, lo relevante en la apreciación contextual o no contextual de la declaración es determinar cuándo se reconoce un problema de rendimiento de la memoria o de la percepción del testigo que impida la punibilidad. Y aquí la cuestión no puede ser sino puramente atributiva: si el testigo declara que "recordaba algo" que no es coincidente con la realidad, el testimonio va a ser igualmente falso si es posible construir la declaración "esto es lo que recuerdo" como falsa por atribuirle otro recuer$\mathrm{do}^{56}$. Eso es lo que hace que la contextualización sólo cambie el portador de la falsedad: desde la declaración como enunciado referido a la verdad de los hechos a averiguar, hacia una declaración sobre el status de la relación entre la realidad y el testigo (es decir: el contenido de su recuerdo). Por supuesto, ese cambio implica una alteración en las cargas argumentativas: si el objeto de la falsedad es el "recuerdo que...", el juez tiene que demostrar que su recuerdo era o (mejor) debía ser otro. Si el objeto de la falsedad es directamente la proposición relativa al estado de cosas sobre el que se declara, el recuerdo distinto funciona como argumento negativo para negar el dolo, lo que sólo necesita ser tematizado argumentativamente si hay una construcción plausible de un argumento de esa clase.

Ello no quiere decir, sin embargo, que las contextualizaciones y la pericia de los interrogadores no jueguen ningún rol ulterior en la verificación del falso testimonio. Las teorías contextuales, más allá de su alcance limitado en el status de las declaraciones, hacen sensibles a la relación dinámica que supone un testimonio. Ello es particularmente importante en relación al problema del falso testimonio por omisión. La imputación por falso testimonio es siempre una imputación de falsedad, esto es, de falta de correspondencia entre la declaración y la realidad. Por eso, el llamado falso testimonio por omisión es conflictivo: la omisión de declarar implica en general ausencia de contenido comunicativo, por lo que no puede ser punible de por si ${ }^{57}$.

Este problema ha aparecido de forma clara en la causa López Ramírez con Carvallo Contreras, correctamente resuelta por la Corte de Apelaciones de San Miguel en $2008^{58}$. La sentencia en cuestión rechazó la apelación del sobreseimiento definitivo de una causa iniciada por querella por falso testimonio. El sobreseimiento definitivo, confirmado por la Corte de Apelaciones de San

\footnotetext{
56 En contra Garrido Montt (2000), p. 114.

57 Similar Vormbaum (1987), p. 270.

58 Corte de Apelaciones de San Miguel, Rol 1284-2008, 13 de octubre de 2008.
} 
Miguel, se había fundado en no ser constitutivos de falso testimonio los hechos objeto de la querella. La querella se refería a las declaraciones producidas por el querellado en un juicio oral por homicidio. Mientras en la etapa de investigación el querellado había dado cuenta pormenorizada de circunstancias que el querellante estimaba relevantes en relación al contexto en que se dio muerte a la víctima, el querellado habría omitido dar buena parte de esa información en el juicio oral. En particular se trataba de la pregunta por si el victimario en el juicio por homicidio había querido "cobrarse", lo que habría sido relevante para la calificación como homicidio calificado. De acuerdo al querellante, la omisión de la declaración sobre ese aspecto, el que sí habría sido considerado en la declaración ante el Ministerio Público, sería constitutiva de falso testimonio. Pero como la Corte de Apelaciones de San Miguel correctamente constató, la ausencia de preguntas a este respecto implica que esa omisión no puede ser constitutiva de falsedad. La mera omisión de información relevante no puede implicar la realización del tipo: la norma de comportamiento del falso testimonio no tiene la misma extensión que la obligación del testigo, sino que se refiere a la obligación de abstención de entrega de información falsa.

Distinto es el caso en que aquello que puede aparecer como una omisión en el contexto de una declaración pueda tener un peso comunicativo pragmático ${ }^{59}$. Si, ante la pregunta por el ánimo de cobrarse del imputado original, el testigo respondiera que "no le consta" o "no lo recuerda" o aún más "jamás había escuchado eso", y a partir de la declaración anterior sea posible considerar que esa declaración sobre su propio recuerdo o percepción es falsa, el tipo se encontraría satisfecho. La modificación del objeto de la declaración puede sobre todo ser utilizada al dar cuenta de las circunstancias de percepción o de recuerdo. La tradicional pregunta "¿cómo le consta?", especificada en preguntas por las circunstancias de la percepción, es particularmente idónea para evitar que la contextualización de la declaración del testigo, reduciendo su contenido a una pura percepción original poco fiable, impida la realización del tipo.

En resumen: "faltar a la verdad" significa declarar algo que no coincide con el objeto de la declaración, cuyo contenido es fijado en el proceso por falso testimonio. Ese objeto es ciertamente definido por la propia declaración, por lo que las respuestas del tipo "recuerdo que..." cambian ese objeto. El cambio contextual que se produce es, sin embargo, dogmáticamente marginal. En lo que es relevante, sólo implica la necesidad del juez de demostrar que la atribución del recuerdo hecha por el propio testigo no es correcta. Pese a ello, las

\footnotetext{
${ }^{59}$ Así también la opinión dominante en la dogmática alemana. Véase Vormbaum (1987), pp. 270-271. En Chile, Rodríguez y Ossandón (2008), p. 249, llegan a una conclusión similar cuando consideran que "la declaración constituye una unidad".
} 
teorías que contextualizan el objeto de la declaración son importantes en el sentido que hacen sensibles a la dinámica del testimonio. La imputación por falso testimonio es en buena medida dependiente de las preguntas que tenga que responder éste.

\section{3. "Declaración": la estructura del delito especial propio y de peligro abstracto}

\section{a) Introducción: la validez del testimonio y la declaración en materia penal}

El contenido del tipo objetivo del falso testimonio puede ser descrito en general a partir de la estructura relacional referida: falta de correspondencia entre enunciado relevante y objeto de la declaración. Esa relación supone, sin embargo, un concepto de "declaración", como descripción del portador válido de falsedad enjuiciado. No todo enunciado emitido en un juicio es idóneo para producir falso testimonio, ya que la mayor parte de las emisiones naturales del sujeto que resulta ser testigo no son, en general, el hecho institucional "declaración". Sólo los enunciados que pueden ser calificados como "testimonio" o "declaración" son de esta forma idóneos para portar falsedad penalmente relevante. Ello tiene una doble explicación. Por una parte, es una exigencia interpretativa sistemática la atribución de sentido a la expresión "su declaración" en el artículo 206 CP de forma vinculada al derecho procesal. Por otra parte, sólo las declaraciones en sentido procesal tienen peso probatorio aunque sea potencial y sólo en ellas se manifiestan las obligaciones principales de los testigos. Si de lo que se trata es de la protección de la administración de justicia frente a actuaciones que pueden tener, en abstracto, peso probatorio, y por lo mismo incidir en abstracto en sentencias, entonces la reducción formal al concepto de declaración es necesaria ${ }^{60}$.

Esa reducción formal no puede, sin embargo, ser exactamente aquello que el derecho procesal consideraría una declaración válida. No sólo es así que la concesión de relevancia formal al testimonio tiene lugar ante todo por consideración de valor probatorio, como demuestran las reglas de inhabilidad de los testigos en los artículos 357-358 CPC. Incluso en la determinación de si existió un hecho institucional "testimonio" del todo, lo que no tiene lugar procesalmente en caso de que posteriormente se declare nulidad procesal por un intervalo que incluya el testimonio en cuestión, no se juega el problema de la existencia de la obligación de declarar la verdad del testigo. Eso quiere decir que las reglas penales de reconocimiento de una "declaración" se encuentran,

${ }^{60}$ Véanse también Kargl (2003), pp. 793-795; Wolf (1991), p. 179, LeNCKNER y BosCH (2010), Vormbem $\S \S 153 \mathrm{ff} . \mathrm{Nm} .2 \mathrm{~s}$. 
en parte, determinadas por las reglas del derecho procesal, pero no se reducen a los criterios de asignación de validez o menos de relevancia probatoria del derecho procesal. Validez procesal y reconocimiento penal no tienen, de esta forma, los mismos criterios.

La reducción del concepto de declaración o, lo que es lo mismo, los criterios penales de reconocimiento de una declaración tienen tres manifestaciones codeterminantes: una reducción formal del sujeto activo, una reducción orgánica de la ocasión en la que el tipo puede realizarse (en causa civil o penal) y una reducción material de la clase de declaraciones en las que puede manifestarse falso testimonio.

\section{b) El falso testimonio como delito especial: sobre el concepto de "testigo"}

La reducción formal del concepto de declaración implica, por una parte, la calificación del falso testimonio como un tipo especial propio. Sólo puede cometer falso testimonio quien reúne las condiciones formales que convierten a alguien en testigo y que, por lo mismo, hacen de su declaración un testimonio. Aquí la calificación del sujeto y de su actuación son co-determinantes: el testigo procesal se reconoce en el testimonio, de la misma forma en que un testimonio sólo puede tener lugar por un testigo. La determinación del concepto de declaración tiene lugar, por ello, también en la determinación del sujeto activo.

En el derecho procesal civil chileno, los testigos se definen por reunir un conjunto de condiciones formales ${ }^{61}$ : negativamente no ser parte y positivamente realizar una actuación procesal en una oportunidad y forma (en general, Ilamado y juramentado, artículo $363 \mathrm{CPC}^{62}$ ) que sea calificable como testimonio.

Eso no quiere decir que tengan que ser considerados testigos válidos, en el sentido que en un sistema de prueba legal tasada como el chileno ello tiene. La determinación de su completa calificación procesal como testigos es relevante para la concesión de valor probatorio a sus declaraciones. El concepto procesal de declaración o testimonio cumple esa función. En materia penal, lo relevante es la producción de la apariencia de una actuación con valor probatorio, con independencia de que tenga valor probatorio real o no: la obligación de no declarar falsedades tiene lugar en todos esos casos. El concepto penal de testigo y declaración no requiere, por ello, que el tribunal sea en definitiva

61 Similar Etcheberry (1998), p. 189; Garrido Montt (2000), p. 110; RodríGuez y Ossandón (2008), pp. 239 y ss.

${ }^{62}$ Véase Rodríguez y OsSAndón (2008), pp. 244-245. La jurisprudencia ha aceptado la interpretación del juramento como requisito formal del testimonio. Así, por ejemplo, la Corte de Apelaciones de San Miguel, Rol 4281-2001, 4 de julio de 2002. 
competente o que no se produzca nulidad procesal posterior ${ }^{63}$. Sí es relevante, en cambio, en que la forma procesal del testimonio tenga lugar. Lo mismo sucede con las inhabilidades. Aunque el derecho procesal civil parece calificar a los testigos inhábiles como no-testigos en los artículos 357 y 358 CPC, una revisión pormenorizada demuestra que se trata de reglas de concesión de valor probatorio. Esto es revelado ante todo por los artículos 357 número 7 y 358 número 6 CPC: la circunstancia de tener interés o de haber sido cohechado tiene que incidir, por cierto, en la concesión de valor probatorio y eso tiene que ser calificado formalmente por el sistema si el sistema de valoración de la prueba es legal tasado. Pero la conclusión de que, en caso de cohecho o parcialidad, el testigo corrompido no tiene responsabilidad penal ${ }^{64}$, se basa en una mala comprensión de las relaciones sistemáticas entre derecho penal y áreas que participan en la definición de sus conceptos normativos. Por supuesto, en varios de los demás casos la inhabilidad del testigo es coincidente con su inimputabilidad. Esa coincidencia muestra, sin embargo, que la razón de la imputación aquí es personal y no se integra, en cambio, al tipo objetivo.

En el derecho procesal penal, sólo constituye testimonio la declaración prestada ante un tribunal y que tenga efectos probatorios posibles. No hay testimonio, en cambio, en la etapa de investigación en las declaraciones a policías y fiscales. Esa conclusión podría ser considerada problemática, ya que el Código Procesal Penal utiliza en distintas instancias los conceptos de declaración y testigo. Así, por ejemplo, el artículo 83 letra d CPP al referirse a declaraciones de testigos presenciales del hecho constitutivo de delito o, ante todo, el artículo 190 CPP, referido a las declaraciones ante los fiscales, utilizan ambos conceptos. El que no constituyen, sin embargo, "declaraciones" para los efectos del artículo 206 CP y siguientes ha sido confirmado formalmente por la introducción de las reglas de obstrucción a la investigación, cuyo objeto era precisamente suplir los vacíos por ausencia de falso testimonio ante fiscales ${ }^{65}$. La única interpretación sistemática plausible es, por ello, considerar que sólo hay declaración, en el

\footnotetext{
${ }^{63}$ La cuestión es similar en la opinión dominante y en la jurisprudencia en el derecho alemán. Al respecto Vormbaum (2013), § 153 Nm. 26 y ss.; Lenckner y Bosch (2010), Vorbem §§ 153 ff. Nm 23. En contra Vormbaum (2013), § $153 \mathrm{Nm} .32$ y ss.

${ }^{64}$ Aunque sin servirse exactamente de este argumento, parte de la doctrina nacional considera que el testigo "no debe tener interés en el juicio". Así, por ejemplo, Politoff et al. (2005), p. 218; y Garrido MONTt (2000), p. 111.

${ }^{65}$ La cuestión podía ser considerada problemática, ya que el Código Procesal Penal utiliza en distintas instancias los conceptos de declaración y testigo. Así, por ejemplo, el artículo 83 letra d CPP al referirse a declaraciones de testigos presenciales del hecho constitutivo de delito. El que no constituye, sin embargo, "declaraciones" para los efectos del artículo 206 CP y siguientes ha sido confirmado formalmente por la introducción de las reglas de obstrucción a la investigación, cuyo objeto era precisamente suplir los vacíos por ausencia de falso testimonio ante fiscales. Al respecto, Ossandón (2008), pp. 421 y ss.
} 
sentido del falso testimonio, cuando tiene entidad de producir prueba, es decir, servir directamente para fundar decisiones judiciales. En esto no es determinante que tenga lugar ante un juez de garantía o tribunal oral, ni de que se trate de actuaciones procesales relativas, por ejemplo, a la imposición de medidas cautelares o, en cambio, a la producción del juicio definitivo de inocencia o culpabilidad del imputado. Lo relevante es que sean actuaciones probatorias, cualquiera sea la clase de resolución que puedan permitir fundar. Ello sucede, por ejemplo, en el artículo 191 CPP (prueba anticipada), pero también cuando se produce prueba testimonial para efectos de dar cuenta del cumplimiento de los requisitos del artículo 140 CPP (prisión preventiva). En particular, además, se encuentra siempre excluida la declaración del imputado como constitutiva de falso testimonio. En esto no hay aplicación del artículo 206 CP inciso final, en el que por lo demás el imputado no está incluido formalmente, sino que se trata de una consecuencia estructural del derecho procesal chileno $(y$, en general, continental).

El derecho procesal chileno ofrece, sin embargo, obstáculos a la interpretación tradicional continental que excluye radicalmente la posibilidad de cometer falso testimonio por una parte o imputado ${ }^{66}$. La pregunta se plantea por la posibilidad no de cometer falso testimonio en la confesión en los términos del artículo $206 \mathrm{CP}$-ya que la calificación formal testigo contra parte/absolvente es a este respecto determinante-, sino por el cumplimiento de las condiciones formales del artículo 210 CP cuando se presta confesión bajo juramento. Como la absolución de posiciones bajo juramento es estructuralmente una declaración juramentada cuya defraudación puede ser, por ello, descrita como perjurio, no es formalmente incorrecto decir que satisface los requisitos del artículo $210 \mathrm{CP}$. Pese a ello, la respuesta a la pregunta de si esa calificación es correcta tiene que ser negativa: las mentiras del absolvente no tienen entidad probatoria (excepto contra sí mismo) y su condición de declaraciones de parte es necesariamente reconocible -a diferencia, por ejemplo, de las inhabilidades de los testigos-, por lo que no hay ni siquiera peligro abstracto aquí. Así lo ha resuelto correctamente la jurisprudencia. La Corte de Apelaciones de Antofagasta, por ejemplo, sostuvo correctamente que el confesante no puede cometer falso testimonio, en los términos de los artículos 206 y 209 CP. El argumento para rechazar la calificación de perjurio, en cambio, es incorrecto (aunque la solución sea co-

\footnotetext{
${ }^{66}$ Esto es distinto, en cambio, en el derecho de los Estados Unidos, en el que la parte y el imputado pueden tener la condición de testigo. Véase PfenNInGer (1957), pp. 366 y ss. La Corte Suprema Federal ha declarado además en reiteradas ocasiones que incluso el testimonio en la investigación que niega falsamente sustentos de la propia culpabilidad (el así llamado "simple no exculpatorio") no caen dentro de protección constitucional y, por lo mismo, son punibles por falso testimonio si las leyes estatales formalmente lo permiten. Así expresamente en Brogan v. United States, en 522 U.S. 398 (1998).
} 
rrecta): de acuerdo a ésta, el artículo $210 \mathrm{CP}$ requeriría que el perjurio tenga lugar en materia no contenciosa ${ }^{67}$. Eso es falso: el artículo $210 \mathrm{CP}$ tipifica alternativamente el "perjurio ante la autoridad" y "el falso testimonio en materia no contenciosa". El confesante, por cierto, no puede cometer por dos razones distintas falso testimonio en materia no contenciosa, pero formalmente puede cometer perjurio ante una autoridad. Su exclusión sólo puede tener lugar, por ello, por argumentos sustantivos.

El propio sistema exime de pena por razones adicionales en otros contextos en el inciso final del artículo 206 CP. Esas razones adicionales, que pueden designarse genéricamente con el nombre de principio de no autoincriminación, dicen relación con una posición: el testigo que se encuentre en una situación del artículo 305 CPP no puede cometer falso testimonio. En esto, hay distribución de competencias entre el derecho procesal penal y el derecho penal. Mientras el derecho procesal penal levanta la obligación procesal de declarar, el derecho penal exime de pena cuando se infringe la obligación de declarar la verdad. El testigo que puede auto-incriminarse o incriminar a un pariente se encuentra en una posición jurídica en que tiene un permiso de no declarar y, pese al mantenimiento de la obligación formal de declarar la verdad si lo decide, la declaración de mentiras no tiene consecuencias relativas a su propia responsabilidad.

\section{c) "Ante un tribunal (...) en causa civil o penal"}

De acuerdo al artículo $206 \mathrm{CP}$, el falso testimonio tiene que ser dado ante "un tribunal" en una causa civil o penal. Al existir tribunales con competencia exclusiva en materia penal, la cuestión de qué es una causa penal ante un tribunal no es problemática. La cuestión de la determinación de qué es una causa civil puede aparecer problemática, en cambio, en los márgenes. Es indudable que un testimonio dado en el probatorio en un juicio de responsabilidad civil ante un tribunal ordinario, por ejemplo, es una causa o proceso civil bajo cualquier concepto que se tenga de éste. Pero la pregunta es aparentemente más compleja en los casos en que tribunal no sea orgánicamente un "Juzgado Civil".

Esta pregunta orgánica puede ser respondida, pese a ello, de forma sencilla. Si bien el concepto de "proceso civil" o de "causa civil" puede significar causa conocida por un tribunal con competencia civil -eso es formalmente posible y la regulación orgánica chilena utiliza a veces el concepto "civil" en ese sentido-, la exclusión del falso testimonio ante tribunales de familia o laborales, por ejemplo, es sustantivamente absurda. Por aplicación del principio de legalidad, ese absurdo sustantivo tendría que ser aceptado si el sistema no proveyera

${ }^{67}$ Corte de Apelaciones de Antofagasta, Rol 132-2007, 29 de junio de 2007. 
argumentos para calificar formalmente un proceso civil de otra forma. Pero la regulación orgánica chilena también utiliza el concepto de causas civiles bajo un sentido puramente negativo, a saber, como causa no penal. Ese es el sentido en que aparece en el artículo $1^{\circ}$ del Código Orgánico de Tribunales o en el artículo 76 de la Constitución Política. El artículo 206 CP tiene de esta forma la misma pretensión taxativa que los artículos referidos. Con ello, los problemas orgánicos son aparentes ${ }^{68}$.

El artículo 210 CP amplía las situaciones de comisión del tipo a los casos de perjurio ante una autoridad o falso testimonio en causa no contenciosa. En esta hipótesis sólo es necesario insistir en un punto: su estructura es equivalente a la del falso testimonio del artículo $206 \mathrm{CP}$, por lo que la clase de restricciones relativas a la forma de la declaración y al contenido de ésta sufren en general sólo modificaciones orgánico-procedimentales, es decir, se trata ante todo de la calificación de qué es un proceso no contencioso y, sobre todo, "una autoridad". Ello puede quedar abierto aquí. Hay un punto, sin embargo, en el perjurio en que la variación es mayor. El juramento no siempre tiene la forma de aseguramiento sobre la veracidad de afirmaciones de hecho, sino también puede cumplir la función de asegurar la promesa de una conducta futura. Esto es así ante todo para los casos de juramentos de autoridades: la estructura de ese juramento es la de una promesa a futuro. Incluso en el proceso sucede algo similar con el juramento de los peritos (o de los árbitros). La interpretación del perjurio como delito de falsedad implica, sin embargo, eliminar la punibilidad por perjurio de la infracción de esa clase de juramentos ${ }^{69}$. El juramento tiene que tener la función de garantizar la reproducción verdadera de hechos.

\section{d) Declaración y su relevancia}

La declaración se define, además, no sólo por referencia a su locutor -el testigo, en el caso de falso testimonio en sentido estricto- sino también por referencia a su contenido. Con razón, tanto la doctrina como la jurisprudencia nacional han tendido a aceptar ampliamente la reducción también sustantiva del concepto de declaración ${ }^{70}$ : sólo constituye declaración el conjunto de enunciados emitido en posición de testigo que tiene entidad abstracta para

\footnotetext{
${ }^{68}$ En sus resultados similar RodríGuez y OSSANDÓn (2008), p. 248.

${ }^{69}$ Todavía BINDING (1904), pp. 135-136, pretendía aplicar el tipo de perjurio a las autoridades que ya tenían al momento del juramento la intención de no ejercer correctamente el cargo. Es difícil ver en qué sentido ello es compatible con su propia visión de los delitos de declaración como afectaciones de medios probatorios. En cualquier caso, con razón concluía Binding que en los casos de incumplimiento de las obligaciones del cargo sólo se trata de eso -violación del juramento, Eidbruch-y no de perjurio -Meineid-.
}

70 Así, por ejemplo, Garrido Montt (2000), p. 114. 
servir de prueba, en el sentido de poder justificar una reconstrucción de los hechos del caso del juez. Ello da pie a una doble calificación: formalmente, la declaración implica emisión lingüística y materialmente la declaración implica relevancia probatoria.

En primer lugar, sólo es declaración la comunicación lingüísticamente mediada. La forma de producción de esa comunicación es definida por el derecho procesal. En general, el derecho procesal chileno la reduce a la forma oral, pero en materia civil el artículo 362 CPC, por ejemplo, permite declarar por escrito. Por otra parte, la clase de pretensión manifestada en los enunciados en juicio tiene que ser afirmativa (o constatativa o descriptiva, como quiera llamársele) ${ }^{71}$. Los así llamados "juicios de valor", pero en general también todo aquello que no pueda ser reconstruido como descripción, no tiene valor probatorio y, por lo mismo, no es susceptible de producir prueba falsa ${ }^{72}$.

En segundo lugar, la declaración tiene que tener potencial probatorio. Eso no quiere decir, por cierto, que tengan que tener esa influencia: el delito de falso testimonio no es un delito de lesión, sino un delito de peligro abstracto ${ }^{73}$. Pero debe tener al menos idoneidad abstracta de producir prueba. Por ello, la declaración tiene que tener relación con el objeto de prueba ${ }^{74}$. En un sistema formalizado, como el proceso civil vigente, la determinación de esa relación se hace por comparación con el auto de prueba. En un proceso sin ese grado de formalidad, la comparación sólo puede ser sustantiva ${ }^{75}$. Además, la declaración debe tener una mínima relevancia en relación con ese objeto. Si el testigo miente, por ejemplo, sobre su propia capacidad física sin que ello tenga

\footnotetext{
71 Así también Vormbaum (2013), § 153 Nm. 3; Kargl (2003), pp. 795-797. En el derecho alemán, la reducción tiende a ser marcada de forma todavía más estricta: la afirmación tiene que referirse a percepciones o sensaciones propias.

72 Eso no quiere decir, sin embargo, que la afirmación no pueda tener por referencia un objeto que supone valoración normativa. No es problemático, por ejemplo, que puede cometerse falso testimonio al dar cuenta que una parte era propietaria de una cosa o celebró un contrato, o que las partes estaban enamoradas o eran amigas, pese a que la calificación propiedad o contrato (o amor o amistad) implique valoración. Así también KARGL (2003), p. 795.

${ }^{73}$ Por supuesto, tratándose de un bien jurídico colectivo, la distinción lesión contra peligro es, en principio, conflictiva: el bien jurídico por definición no se ve afectado directamente por acciones individuales. De lo que se trata en la calificación del peligro abstracto en el falso testimonio es mucho más sencillo: no debe tener incidencia directa en una sentencia posterior. Sobre la estructura de peligro abstracto del falso testimonio, véase con mayor detalle WILENMANN (2011), p. 567 y KINDHäUSER (2009), pp. 15-18.

74 Así Vormbaum (1987), p. 249; Vormbaum (2013), § 153 Nm. 9-12; Otto (1984), p. 164.

75 Así también, por ejemplo, en el derecho penal alemán. Véase sólo Отто (1984), p. 164, con ampliaciones en la reducción al contenido del auto de prueba.
} 
ninguna relevancia en el juicio, no se satisface el tipo: no es una "declaración" para estos efectos ${ }^{76}$.

En la doctrina y jurisprudencia nacional, la aceptación inicial de esa reducción abstracta tiende a tener lugar de forma confusa. Así, por ejemplo, en el año 2010 en la causa Metrogas S.A. con Hernán Uribe, la Corte de Apelaciones de Santiago sostuvo que las afirmaciones que no producen efectos procesales relevantes se ven excluidas del tipo, especificando que las razones por las que ello tiene lugar se debe a que en esos casos no hay consumación del tipo por no producción, en el fondo, de daño procesal ${ }^{77}$. La referencia a la consumación muestra el error que se encuentra detrás: la Corte de Apelaciones, intentando sostener un criterio sensato de reducción del concepto de declaración a actuaciones procesales con entidad probatoria abstracta, sostuvo que se trata de un delito de resultado y de lesión. Eso es incompatible con la estructura del falso testimonio.

\subsection{Falsa traducción, falso peritaje y testigos expertos: sobre la extensión de la aceptación de las teorías modificadas}

Desde la reforma del año 2005, el Código Penal chileno incluye, en realidad, tres tipos distintos a propósito del falso testimonio. Más allá del falso testimonio, el artículo 206 tipifica el falso peritaje y la falsa traducción. Al igual que en el falso testimonio, el intérprete y el perito, y correlativamente la traducción y el peritaje, se encuentran definidos formalmente por el derecho procesal. Dar cuenta de esas limitaciones formales no es de interés aquí. Sólo es importante mostrar la forma en que varía el concepto de falsedad: falsedad ya no puede ser (sólo) falta de correspondencia con la realidad referida. El concepto de falsedad tiene que modificarse aquí por consideración de roles procesales. Y los roles del perito y del intérprete no son equivalentes al del testigo. Tan clara es esta diferencia, en el caso del perito, que el artículo 227 número $3 \mathrm{CP}$ equipara su posición en la administración de justicia a la de los jueces. Por supuesto, esa equiparación sólo tenía sentido sistemático cuando los peritos no podían cometer falso peritaje. Con la modificación del año 2005, el castigo doble por prevaricación del perito y falso peritaje es injustificable. El error legislativo muestra, sin embargo, las distintas funciones que cumplen peritos y testigos.

La determinación del sentido en que un peritaje o una traducción son falsos sólo puede tener lugar por determinación de su rol procesal. A diferencia de los testigos, el perito es un experto: no sólo suple el déficit cognitivo del juez por su separación respecto de los hechos, sino que además suple las deficiencias técnicas que éste puede tener en materias complejas. Esto da lugar a una dife-

76 Similar Vormbaum (1987), pp. 249 y ss.

77 CSAN Rol 927-2010, CL/JUR/12204/2010. 
rencia relevante: el razonamiento del perito tiene valor probatorio, mientras en principio el razonamiento del testigo no debiera tenerlo. Con ello, la falsedad del peritaje no es sólo descripción imputablemente falsa en sentido estricto. El peritaje también es falso cuando, sin reproducir falsedades en los datos, expone un razonamiento manifiestamente falso, con irrelevancia de que ello tenga lugar por ausencia de lógica interna, por aplicación errada de principios de causalidad aplicables al caso u otra causa ${ }^{78}$.

En esto, es problemática la determinación de si la actuación de peritos en oportunidades distintas del informe constituye falso testimonio y, por ello, tienen que asumir sus limitaciones, o falso peritaje. Esto es crucial a la luz de la práctica procesal común consistente en hacer que peritos declaren como testigos. Algo similar sucede en los casos en que un testigo se presenta (o es presentado) como experto, ya sea porque ha evacuado un informe que no constituya pericia en los términos de los artículos 409 y siguientes CPC o sin que ello tenga lugar. La pregunta es si su declaración valorativa falsa también implica falso testimonio. La respuesta tiene que ser en todos los casos afirmativa en materia penal: en un sistema de valoración de la prueba por sana crítica, la presentación personal como experto y su declaración en esa calidad tiene entidad probatoria abstracta $^{79}$. En materia procesal civil, en cambio, la cuestión es más compleja. En principio, las declaraciones de testigos tienen otro efecto probatorio que las pericias. Con ello, la declaración del experto puede en los hechos producir convicción, pero no tiene el status probatorio de un testimonio válido. La aceptación en este caso, en que no hay valoración de la prueba por sana crítica, de la punibilidad por falso testimonio es, por lo mismo, problemática.

En el caso de la falsa traducción, la determinación del contenido de la falsedad es más sencilla. Una traducción es falsa cuando no es reproducción suficientemente verosímil del sentido original de lo manifestado en otro idioma.

\subsection{Presentación de pruebas falsas e inducción al falso testimonio}

El artículo 207 del Código Penal contiene dos hipótesis típicas que pueden ser distinguidas. Por una parte, la presentación de testigos (o peritos e intérpretes) falsos ha tenido históricamente un tratamiento especial. El derecho común, por ejemplo, tendió a reconocer reglas de castigo equivalente del inductor al falso testimonio que del testigo falso ${ }^{80} \mathrm{O}$, incluso, reglas superiores, basado en el argumento de Agustín respecto a que el inductor al perjurio mata dos almas: la

\footnotetext{
78 Similar Vormbaum (1987), p. 260; Kindhäuser (2012), § 46 Nm. 11.

79 Esta es la verdad de las teorías modificadas (o de las expectativas/obligaciones procesales) de la declaración falsa. Al respecto, véase sólo Vormbaum (1987), pp. 255 y ss.; y Otтo (1984), p. 162.

${ }^{80}$ Así Liszt (1876), pp. 84-85.
} 
de quien realiza el perjurio y la suya ${ }^{81}$. Por otra parte, el artículo 207 CP tipifica la presentación de otros medios de prueba falsos o adulterados.

El primer tipo, pese a constituir un tipo autónomo, tiene una estructura accesoria. Se trata en realidad de la misma regla que en el derecho común, a saber, que la pena por la presentación del testigo falso a sabiendas es la misma que la del testigo falso. Ello quiere decir que su consumación requiere de producción del falso testimonio. Sin ella, sólo puede haber tentativa. Pese a que la regla puede cumplir un rol perlocucionario importante, en el sentido de remarcar el injusto de presentar testigos falsos, sigue manteniendo de esta forma la estructura de la inducción al falso testimonio. Además, ni siquiera hace superflua la construcción con categorías de la Parte General, ya que la inducción puede tener lugar sin que esa acción sea constitutiva de la calificación procesal "presentar" propia de abogados y partes.

El segundo tipo es, en cambio, autónomamente relevante. El tipo es, al igual que el falso testimonio, dependiente de criterios de reconocimiento del hecho institucional "presentar pruebas" cuyo contenido es fijado con atención a las reglas del derecho procesal, pero que no tiene los mismos requisitos de validez que éste. Esto es relevante ante todo en los casos de declaración posterior de nulidad procesal.

La realización del tipo supone solamente el reconocimiento procesal (aunque sea plausiblemente aparente) de una presentación de prueba y que esa prueba sea conocidamente falsa. La falsedad aquí puede serlo en sentido estricto o no, como se deduce claramente de la utilización del "adulterada". Con ello, es irrelevante que un documento público adulterado dé cuenta en su contenido de la verdad. Su peso probatorio es otro que su peso real y, por ello, califica como presentación de pruebas falsas. También es irrelevante que el documento cuyo contenido sea falso sea simplemente privado y, por lo mismo, en general impune de acuerdo al sistema de delitos de falsedad documental. La parte que ante-data un documento en que se atribuye a sí mismo declaraciones que no hizo hasta forjar el instrumento en cuestión puede, con ello, cometer el delito de presentación de pruebas falsas. No hay continuidad entre delitos de falsedad documental y delito de presentación de pruebas falsas.

\section{La imputación del falso testimonio: el dolo bajo una comprensión objetiva del falso testimonio}

La defensa de una teoría objetiva de la declaración falsa hace crucial la aclaración del status de la imputación del falso testimonio. Si un testimonio es falso simplemente por ausencia de correspondencia con la realidad (o, mejor, con la reconstrucción justificada del juez), entonces falso testimonio se comete

81 MüLler (2000), p. 17. 
objetivamente con independencia de la consideración de la declaración como mentira. Esta es la verdad de las teorías subjetivas: no puede considerarse que haya infracción de obligación del testigo que reproduce lo que sabe cuando su conocimiento es justificadamente incorrecto. Esos problemas pueden resolverse, como se ha dicho, con una comprensión correcta del dolo, en particular en un sistema como el chileno en que no existe el delito de falso testimonio imprudente. Comprensión correcta quiere decir dos cosas: comprensión correcta en la Parte General respecto a los criterios de atribución de dolo y, sobre todo, al rol que cumple el dolo; y comprensión correcta de las consecuencias que ello tiene en el delito de falso testimonio.

En delitos que no pueden ser imputados extraordinariamente (no hay imputación por imprudencia) el dolo es el único criterio que permite atribuir la infracción de la norma de comportamiento penal. En todo otro caso, la producción del estado de cosas antinormativo es casual de acuerdo a las reglas del sistema y no se deja, por ello, designar como infracción de su obligación. En el falso testimonio, ello implica que la producción de una afirmación falsa no imputable no tiene relevancia alguna penal. Ello no quiere decir, por cierto, que sea necesario verificar siempre que el testigo sepa que está declarando algo falso. Al igual que en toda la dogmática del dolo, la imposibilidad de acceso a estados mentales hace que sus criterios no puedan sino ser atributivos (no verificativos). De lo que se trata, por ello, es de atribuirle conocimiento de la falsedad ${ }^{82}$. Intención de falsedad o provecho por la falsedad son elementos en esto innecesarios: pueden ser indicativos de algo, pero no son necesarios para atribuir dolo ${ }^{83}$. Esto es precisamente lo que hace que las teorías subjetivas sean insalvablemente imperfectas. Suponen que sólo puede haber falsedad allí donde hay falta de correspondencia entre declaración y conocimiento, pero en general no se encuentran en condiciones de construir el conocimiento. Con ello, no pueden sino comportarse atributivamente, al igual que las teorías objetivas ${ }^{84}$.

\footnotetext{
82 Por ello, la pretensión de Garrido Montt (2008), p. 115 y de Rodríguez y Ossandón (2008), p. 254, de excluir el dolo eventual, con el argumento de que el que se equivoca no miente, es difícilmente comprensible. El propio Garrido Montt admite, sin embargo, en la nota a pie de página 21 que su afirmación es discutible.

${ }^{83}$ En esto es correcta la decisión de la Corte de Apelaciones de Punta Arenas, Rol 39-2006, 9 de mayo de 2006, en Juan Chiguay contra Tribunal Oral en lo Penal de Punta Arenas, la que rechazó las alegaciones del recurrente de nulidad en relación a que la ausencia de elementos que indicaran ánimo o provecho de mentir impedían la imputación por dolo. Por supuesto, es falso que ello transforme al dolo, como pretende la Corte de Apelaciones, en un "elemento psicológico". Una consideración de esta clase se encuentra completamente superada en la dogmática de la Parte General actual. La conclusión es, en cualquier caso, correcta.

${ }^{84}$ HrusChKA Y KäsSER (1972), p. 710, denominan, por ello, a las teorías sin fijación potencial (normativa) en la percepción o en el recuerdo como "subjetivas extremas" y las descartan. Toda teoría subjetiva tiene que ser, en realidad, potencial, es decir, no exactamente subjetiva.
} 
En la imputación de la falsedad, la declaración fija el contenido de aquello que tiene ser conocido. El testigo tiene que saber, por ello, que está declarando (su posición de testigo, ante un tribunal, etc.) y que el contenido de su declaración no es coincidente con su elemento de comparación (conocimiento de la falsedad $)^{85}$. En caso de contextualización del objeto como su recuerdo o su percepción, el objeto de comparación varía y, por ello, la atribución de conocimiento de la falsedad de la declaración se adapta a ello: el testigo tiene que saber que su declaración sobre el contenido de su recuerdo es falsa. Pero, como tampoco es posible acceder a estados mentales aunque el testigo declare que el objeto de su declaración es el recuerdo, también aquí el objeto final de comparación va a ser la reconstrucción alternativa del juez del estado de cosas recordado. Al igual que en los demás casos, la construcción de circunstancias que hacen plausible la existencia de un recuerdo (o percepción) errado sólo influye, por ello, en la construcción de un error. Ese error va a impedir la imputación en el caso normal y va a impedir, en cambio, la verificación del tipo objetivo en los demás casos. Pero la distinción no tiene relevancia: es sólo precisión.

\section{Bibliografía CitADA}

BERNER, Albert Friedrich (1866): Lehrbuch des deutschen Strafrechtes, $3^{\text {a }}$ edición (Leipzig, Bernhard Tauchnitz).

BINDING, Karl (1904): Lehrbuch des gemeinen deutschen Strafrechts. Besonderer Teil, Band 2, 2a edición (Leipzig, Engelmann).

BINDING, Karl (1911): "Vier Forderungen an das künftige Reichsstrafgesetzbuch und eine fünfte and die Motive seines Entwurfes", en: Der Gerichtssaal 77 (Stuttgart, Ferdinand Ente), pp. 1-21.

Etcheberry, Alfredo (1998): Derecho Penal, $3^{a}$ edición (Santiago, Editorial Jurídica), tomo IV.

FeuerBACH, Paul Johann Anselm (1812): Lehrbuch des gemeinen in Deutschland gültigen peinlichen Rechts, $5^{\text {a }}$ edición (Gießen).

Gallas, Willhelm (1957): “Zum Begriff der 'Falschheit' der eidlichen und uneidlichen Aussage", en: Goltdammer's Archiv für Strafrecht, pp. 315-325.

Garrido Montt, Mario (2000): Derecho Penal Parte Especial (Santiago, Editorial Jurídica), tomo IV.

HiLGendoRf, Eric (1993): "Der Wahrheitsbegriff im Strafrecht am Beispiel der strafrechtlichen Aussagetheorien (§§ $153 \mathrm{ff} . \mathrm{StGB}$ )", en: Goltdammer's Archiv für Strafrecht, pp. 547-559.

${ }^{85}$ Véase Vormbaum (2013), § 153 Nm. 102 y ss. 
HRUSCHKA, Joachim y KäSSER, Wolfgang (1972): "Der praktische Fall. Strafrecht: Die Eidesbrüder", en: Juristische Schulung, pp. 709-715.

KaufmanN, Arthur (1992): "Die strafrechtlichen Aussagentheorien auf dem Prüfstand der philosophischen Wahrheitstheorien", en: Arzt et al. (eds.), Festschrift für Jürgen Baumann (Bielefeld, Verlag Ernst und Werner Gieseking), pp. 119-130.

KARGL, Walter (2003): "Wahrheit und Wirklichkeit im Begriff der 'falschen Aussage' (§§ 153 ff. StGB)", en: Goltdammer's Archiv für Strafrecht, pp. 791-806. KINDHÄUSER, Urs (2012): Strafrecht Besonderer Teil I, $5^{a}$ edición (Baden-Baden, Nomos).

KINDHÄUSER, Urs (2009): "Estructura y legitimación de los delitos de peligro", en: InDret (1).

KüPER, Wilfried (2005): Strafrecht Besonderer Teil (Heidelberg, Müller).

LeNCKNER, Theodor y BOSCH, Nikolaus (2010): Comentario "Vorbem. §§ 153 ff.", en: Eser et al. (eds.), Schönke/Schröder Strafgesetzbuch Kommentar, 28 edición (Múnich, Beck).

LIzST, Franz v. (1876): Meined und falsches Zeugniss (Viena).

MAIHOLD, Harold (2006): "'auß lieb der gerechtigkeyt vnd umb gemeines nutz wiIlen' - Die Constitutio Criminalis Carolina von 1532", en: Iusfull, pp. 76-86.

MülLER, Henning Ernst (2000): Falsche Zeugenaussage und Beteiligungslehre (Tubinga, Mohr Siebeck).

MülleR, Henning Ernst (2012): Comentario "Vor §§ 153 ff." y "153 StGB", en: Joecks y Miebach (eds.), Münchener Kommentar zum Strafgesetzbuch (Múnich, Beck), tomo 3.

Ossandón, María Magdalena (2008): "Los delitos de obstrucción a la investigación", en: Rodríguez Collao (ed.), Delitos, pena y proceso. Libro homenaje a Tito Solari Peralta (Santiago, Editorial Jurídica).

Отто, Harro (1984): "Die Aussagedelikte, §§ 153-162 StGB", en: Juristische Schulung, pp. 161-172.

Pfenninger, H.F. (1957): "Die Wahrheitspflicht des Beschuldigten im Strafverfahren", en: Hohenleitner et al. (eds.), Festschrift für Theodor Ritter (Aalen).

Politoff, Sergio; Matus, Jean Pierre; y Ramírez, María Cecilia (2005): Lecciones de Derecho Penal Chileno, Parte Especial, Segunda Edición (Santiago, Editorial Jurídica).

PAulus, Rainer (1987): “Die 'falsche Aussage' als Zentralbegriff der §§ 153-163 StGB", en Just et al. (eds.), Gedächtnisschrift für Günther Küchenhoff(Berlín, Duncker \& Humblot), pp. 435-456.

Rodríguez, Luis y Ossandón, María Magdalena (2005): Delitos contra la función pública, $1^{\text {a }}$ edición (Santiago, Editorial Jurídica). 
Rodríguez, Luis y Ossandón, María Magdalena (2008): Delitos contra la función

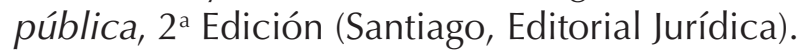

Schmidt, Richard (1909): "Die Lüge im Prozess", en: Deutsche Juristen Zeitung, pp. 39-45.

Stein, Ulrich (2008): "Acerca del concepto de declaración falsa", en: Revista Electrónica de Ciencia Penal y Criminología (10-15). Disponible en: http:// criminet.ugr.es/recpc/10/recpc10-15.pdf [visitado el 29/05/2013].

Vormbaum, Thomas (1987): Der strafrechtliche Schutz des Strafurteils (Berlín, Duncker Humblot).

Vormbaum, Thomas (2013): Comentario "Vor §§ 153 ff." y "§ 153 StGB", en: Kindhäuser, Neumann y Paeffgen (eds.), NomosKommentar, Strafgesetzbuch, $4^{\text {a }}$ edición (Baden-Baden, Nomos), tomo 2.

WilenmanN, Javier (2011): "La administración de justicia como un bien jurídico", en: Revista de Derecho de la Pontifica Universidad Católica de Valparaíso (36), pp. 531-573.

WilenmanN, Javier (2013): "Injusto, tipo e imputación. La teoría de la antijuridicidad en la dogmática penal", en: Mañalich (ed.), La antijuridicidad en el derecho penal, cuatro estudios (a publicarse en B de F, Montevideo-Buenos Aires).

WilenmanN, Javier (2014): "El concepto de falsedad en el falso testimonio. Una introducción a la dogmática de los delitos de falsedad", en: Revista Chilena de Derecho (vol. 41, № 1), pp. 59-88.

Wotf, Gerhard (1991): "Falsche Aussage, Eid und eidesgleiche Beteuerungen", en: Juristische Schulung, pp. 177-184.

\section{JURISPRUDENCIA CITADA}

Brogan v. United States, en 522 U.S. 398 (1998).

Segundo Juzgado del Crimen Maipo Alto Buin con Madariaga Rodríguez (2002): Corte de Apelaciones de San Miguel, 4 de julio de 2002, Rol 4281-2001, en: CL/JUR/1111/2002.

Juan Chiguay con Tribunal Oral en lo Penal de Punta Arenas (2006): Corte de Apelaciones de Punta Arenas, 9 de mayo de 2006, Rol 39-2006 en: CL/ JUR/738/2006.

Corte de Apelaciones de Antofagasta (2007), 29 de junio de 2007, Rol 132-2007, en: CL/JUR/1259/2007 (nombre de partes no disponible).

López Ramírez con Carvallo Contreras (2008): Corte de Apelaciones de San Miguel, 13 de octubre de 2010, Rol 1284-2008, en: CL/JUR/5585/2008. 